APDA * NTS - I

\title{
INITIAL LOADING TO CRITICALITY OF THE ENRICO FERMI REACTOR
}

\author{
By \\ R. E. Mueller \\ C. 도. Branyan \\ J. E. Nims
}

May 1964 


\section{DISCLAIMER}

This report was prepared as an account of work sponsored by an agency of the United States Government. Neither the United States Government nor any agency Thereof, nor any of their employees, makes any warranty, express or implied, or assumes any legal liability or responsibility for the accuracy, completeness, or usefulness of any information, apparatus, product, or process disclosed, or represents that its use would not infringe privately owned rights. Reference herein to any specific commercial product, process, or service by trade name, trademark, manufacturer, or otherwise does not necessarily constitute or imply its endorsement, recommendation, or favoring by the United States Government or any agency thereof. The views and opinions of authors expressed herein do not necessarily state or reflect those of the United States Government or any agency thereof. 


\section{DISCLAIMER}

Portions of this document may be illegible in electronic image products. Images are produced from the best available original document. 


\section{FOREWORD}

This report is one of a series of reports on the low-power (up to 1 Mwt) and high-power (up to $200 \mathrm{Mwt}$ ) nuclear testing of the Enrico Fermi fast breeder reactor. The Nuclear Test Program is planned, directed, and evaluated by Atomic Power Development Associates, Inc., (APDA). The tests are conducted by Power Reactor Development Company, (PRDC). The reactor proper is owned and operated by PRDC. The steam generators and electrical generation facilities are owned by The Detroit Edison Company, (DECO).

Many people have contributed to the success of the nuclcar testing of the Fermi reactor. Listed below are the names of those people, exclusive of the authors, who made a significant contribution to some phase of the work reported in this document.

\section{APDA}

R. J. Beaudry

R. E. Horne

H. A. Wilber

\section{PRDC}

E. L. Alexanderson

C. H. Clark

D. Erdman

W. J. McCarthy

W. R. Olson

R. G. Ratieck

\section{DECo}

D. F. Gasvoda

P. M. Harrigan

O. E. Homeister

K. Johnson 


\section{TABLE OF CONTENTS}

$\underline{\text { Page }}$

LIST OF ILLUSTRATIONS .................. 4

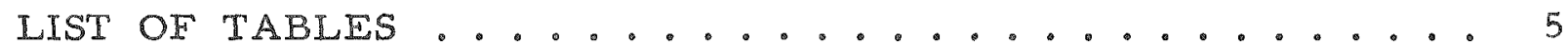

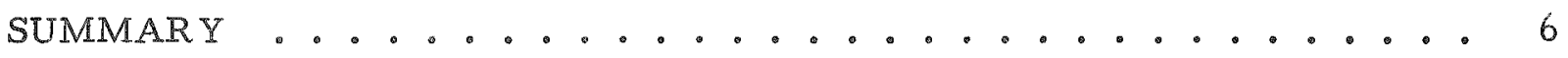

I. PURPOSE OF TEST .................... 7

II. DESCRIPTION OF THE ENRICO FERMI REACTOR CORE。 . . 8

III. EXPERIMENTAL PROCEDURE .............. 14

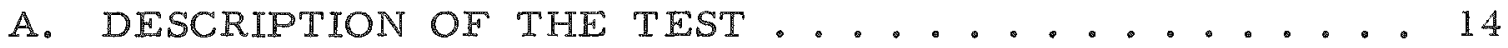

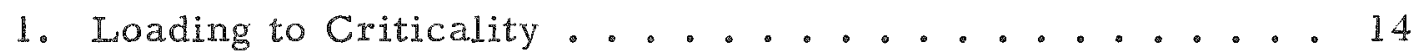

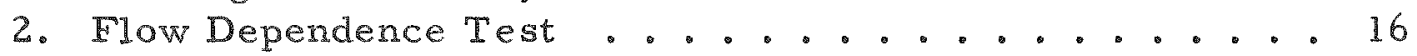

3. Reactivity Measurements ............ 16

B. NEUTRON SOURCE AND INSTRUMENTATION ...... 16

1. Neutron Source .................... 16

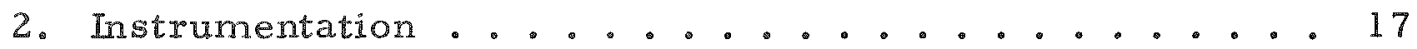

IV. EXPERIMENTAL RESULTS .............. 21

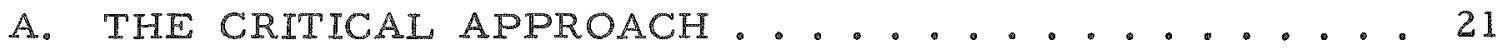

1. Condition of Reactor Prior to Critical Approach . . . . . 21

2. Loading to Criticality ............. 24

3. Determination of Critical Mass .......... 42

B. REACTIVITY EFFECTS ................. 43

1. Control Rod Calibration............. 43

2. Worth of the Temporary Instrument Thimble ..... 47

3. Worth of a Shim Fuel. Subassembly at Core Edge .... 47

4. Replacement Worth of Inner Radial Blanket

Subas semblies for Dummies .......... 47

5. Effect of Sodium Coolant Flow Rate on Reactivity .... 49

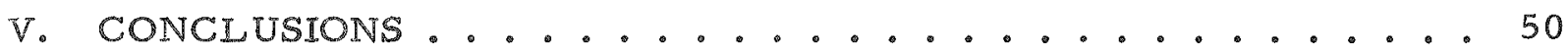

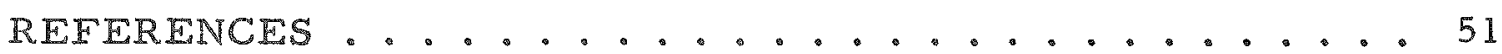

ACKNOWLEDGEMENTS ................... 52 


\section{LIST OF ILLUSTRATIONS}

Eigure

Title

$\underline{\text { Page }}$

1 Perspective View of Reactor ............. 9

2 Reactor Cross Section .............. 10

3 Location of Neutron-Counter Tubes in Graphite Shield . . . 12

4 Neutron-Counter Tubes Nos. 3 and 4, Showing the Location of the Detectors During the Critical Approach . . . . . . 18

5 Core Configuration Prior to Critical Approach . . . . . 22

6 Subassembly Loading Sequence Diagram .......... 27

7 Inverse Count Rate versus Loading Curves-- $\mathrm{C}_{\mathrm{O}} / \mathrm{C}_{\mathrm{N}}$ vs $\mathrm{N} . .32$

8 Inverse Count Rate versus Loading Curves-- $C_{0} / C_{N}$ vs $\sqrt{N}$. 33

9 Inverse Count Rate versus Loading Curves-- $\sqrt{\mathrm{N}} \cdot \mathrm{C}_{\mathrm{O}} / \mathrm{C}_{\mathrm{N}}$ vs $\mathrm{N} \quad 34$

10 Inverse Count Rate versus Loading Curves- $-\mathrm{N} \cdot \mathrm{C}_{\mathrm{O}} / \mathrm{C}_{\mathrm{N}}$ vs $\mathrm{N} \cdot 35$

11 Inverse Count Rate versus Loading Curves-- $C_{D} / C_{U}$ vs $N$. 37

12 Predicted Critical Loading versus Loading Curves for Channel A ................. 39

13 Predicted Critical Loading versus Loading Curves for Channel 3 ................. 40

14 Predicted Critical Loading versus Loading Curves for

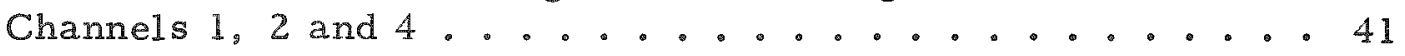

15 Regulating Rod Calibration Curve . . . . . . . . . 45 


\section{LIST OF TABLES}

Table

Title

Page

I. Count Rates Prior to the Critical Approach ......... 23

II. Fuel Subassembly Loading Increments ........... 26

III. Corrected Subcritical Multiplication Count Rates . . . . . 28

IV. Source Decay Correction Factors ............ 29

V. Gas Correction Factor for Channel A and "Source Shine"

Correction Factor for Channel 3 .......... 30

VI. Detector Reaction Correction Factors for Channels 1, 2 and 430

VII. Predicted Critical Loading versus Loading Values . . . . 38

VIII. Reactivity Measurements . . . . . . . . . . . . . 44

IX. Control Rod Worths Obtained from Inverse Count Rate Curve Extrapolations .............. 48 


\section{SUMMARY}

The loading of fuel into the Enrico Fermi reactor began on July 24, 1963. Criticality was achieved at 12:23 p.m. on August 23, 1963, when the reactor diverged on a 178 -second period with 99 fuel subassemblies loaded. The entire loading sequence proceeded with remarkable smoothness. No spurious scrams occurred and the only delay in the schedule was a minor one brought about by maintenance on the transfer rotor mechanism.

Near the end of the loading sequence, subcritical measurements were made to detect whether any significant reactivity effects existed due to primary sodium coolant flow. No flow effects were observed.

After the critical loading was achieved, further measurements were made to obtain preliminary reactivity worths of the regulating control rod, the temporary in-core instrument thimble, an edge fuel subassembly, and several inner radial blanket subassemblies. The last of these measurements was completed on September 3, 1963. All measurements were in good agreement with the predicted values. 


\section{PURPOSE OF TEST}

The Enrico Fermi Reactor Loading-to-Critical Test was performed to attain an initial critical loading for the reactor. The critical mass determined by this test was utilized as a reference for all subsequent nuclear tests and it served as a comparison with critical mass calculations and critical experiment work conducted for the Fermi reactor. The reactivity worth determinations made shortly after criticality have aided in the planning and evaluation of subsequent tests. The Initial Loading-to-Critical Test was performed in accordance with a written, preplanned program. ${ }^{1}$ A detailed description of the Fermi reactor is given in the Enrico Fermi Hazards Summary Report. ${ }^{2}$ 


\section{DESCRIPTION OF THE ENRICO FERMI REACTOR CORE}

The Fermi reactor core and its associated structures are shown in perspective in Figure 1. The reactor is contained in a stainless steel reactor vessel sealed at the top by a rotating shield plug which supports the control mechanisms, the hold-down mechanism, and the fuel handling mechanism. The reactor vessel is surrounded by borated graphite and plain graphite neutron shielding material which is contained inside the primary shield tank. The reactor is of the fast-breeder type, cooled by sodium, and operated at essentially atmospheric pressure. The maximum reactor power with the first core loading is $200 \mathrm{Mwt}$.

The core and blanket, located in the lower reactor vessel, consist of square subassemblies containing the fuel pins and blanket rods arranged to approximate a cylinder about 80 -inches in diameter and 70 inches high. The core, contained in the central portion of the core subassemblies, approximates a right cylinder 31 inches in diameter and 31 inches high; it is axially and radially surrounded by breeder blankets. The fuel in Core A consists of zirconium-clad pins containing $U-10 \mathrm{w} / 0$ molybdenum alloy with the uranium enriched to 25.6-percent U-235. Each fuel subassembly in the core contains 140 fuel pins for a total mass of 4.75 kilograms of $U-235$ per subassembly. The blanket is depleted $U-3 \mathrm{w} / 0$ molybdenum alloy.

The reactor cross section, shown in Figure 2, indicates the placement of individual components within the lower reactor vessel. There is a total of 149 central lattice positions that are occupied by core and inner radial blanket subassemblies, the neutron source, and the 10 operating control and safety rod channels. All these positions are supplied with sodium coolant flowing upward from a high pressure plenum which is connected to the discharge lines of the three primary sodium pumps. The coolant flows upward through the individual core and inner radial blanket subassemblies into a large upper plenum and then by gravity to the three intermediate heat exchangers and then to the suction side of the primary pumps. Sodium also is used in the secondary cooling system.

The lattice positions surrounding the inner radial blanket comprise the outer blanket area and when filled with outer radial blanket subassemblies, form an annular region whose top and bottom are at the same elevation as the top and bottom of the inner radial blanket. Surrounding the outer radial blanket are lattice positions used for stainless steel subassemblies. These subassemblies proviảe thermal and neutron shielding. The outer radial blanket and shielding lattice positions are supplied with sodium coolant from a low pressure plenum. 


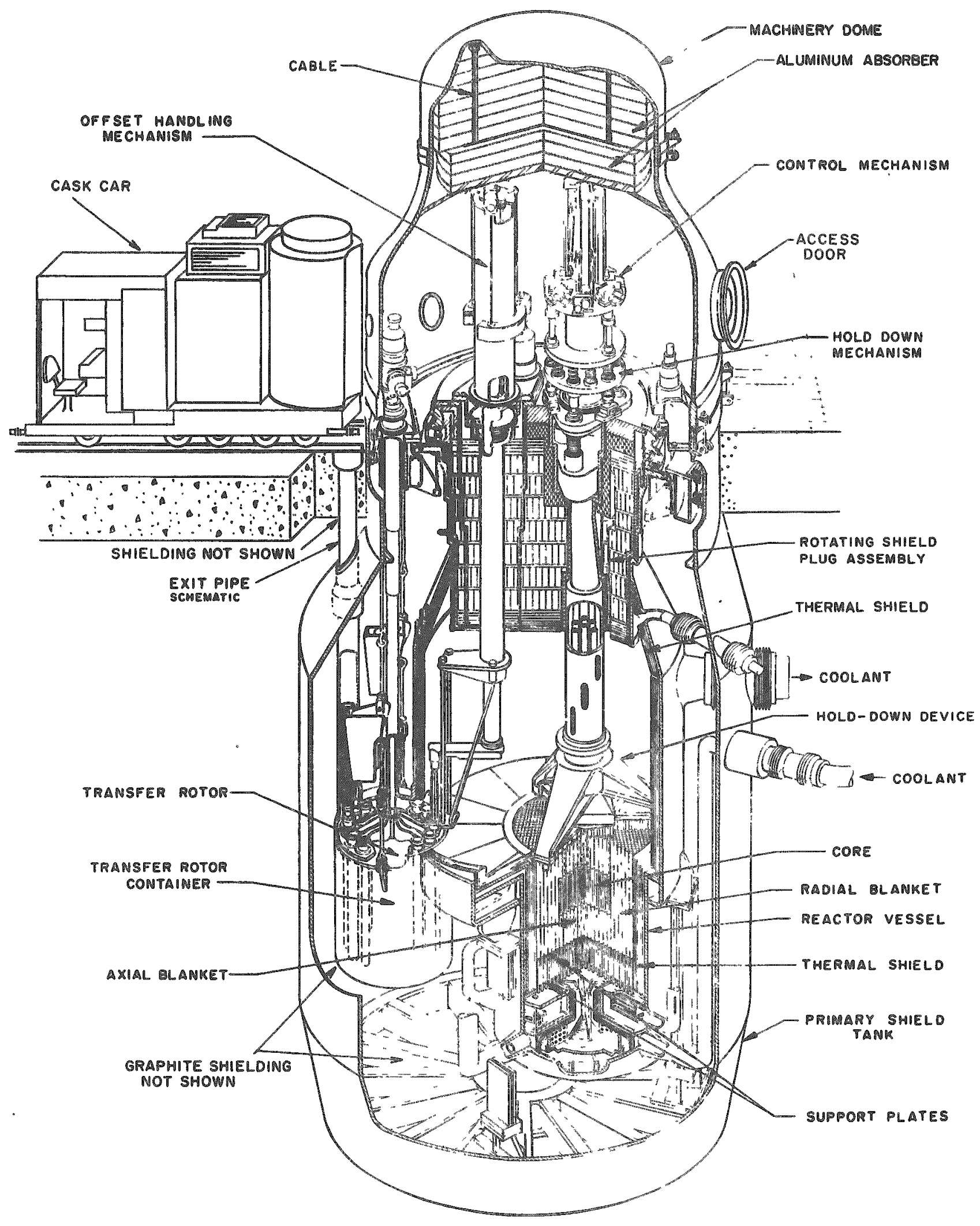

FIG. I PERSPECTIVE VIEW OF REACTOR 
The reactor is controlled by two operating control rods and eight safety rods. The rods are of the poison type, containing boron carbide $\left(\mathrm{B}_{4} \mathrm{C}\right)$ in which the boron is enriched in boron-10 (B-10). One operating control rod is for regulating purposes and the other for shimming; the average reactivity insertion rates of these rods are approximately one cent per second and one cent per minute, respectively. The eight safety rods, which are uniformly spaced around the center of the core, provide shutdown reactivity. During operation of the reactor, the safety rods are held just above the axial blanket section of the core so that they can be rapidly inserted into the core if a scram becomes necessary. During a normal shutdown, the rods are slowly lowered by motor into the core where they remain during refueling to provide the necessary shut-down reactivity. The control and safety rods are driven and actuated from the top. They are delatched from their drive extensions to allow them to remain in the core during reloading. The reactor is operated manually during start-up and during operation at p. wers below that providing sensible heat generation.

The neutron detectors (fission chambers and ion chambers), for reactor operation at power, are located in six neutron-counter tubes (NCT) embedded in the graphite neutron shield surrounding the reactor vessel (Figure 3). These detectors are designed to operate at temperatures up to $500 \mathrm{~F}$. Borated graphite is kept away from the region of the counter tubes to minimize interference with the response of the detectors. One of the counter tubes (NCT No. 4) is surrounded by lead shielding to reduce the gamma background from a nearby primary sodium coolant pipe. The detectors are nominally located at the core midplane for maximum sensitivity, but they can be positioned vertically inside the counter tubes if desired. The eleven channels of nuclear instrumentation are distributed throughout the six neutron-counter tubes in a manner which will cover the full power range during reactor operation. The two source range channels are supplied by signals from two fission chambers and cover the range from shutolown source power to about $12 \mathrm{kw}$. The three intermediate power range channels are supplied by signals from compensated, B-10 lined ion chambers which operate from approximately $1.2 \mathrm{kw}$ to $1200 \mathrm{Mw}$, thus providing an overlap of one decade with the source-range chamels. The six power range channels consist of ion chambers which are uncompensated, and cover the range from $2 \mathrm{Mw}$ to $300 \mathrm{MW}$ (1 to 150 per cent of full power).

An antimony-beryllium ( $\mathrm{Sb}-\mathrm{Be}$ ) neutron source is located in the reactor at the core-blanket interface (Figure 2) to provide a neutron flux at the neutron detectors during reactor startup and to maintain a flux when the reactor is shutdown. The radioactive antimony portion of the source is made as a separate piece for easy replacement and is in the form of a rod approximately 0.7 inches in diameter and 25 inches long. The radioantimony rod fits inside a beryllium assembly which is in the form of a hollow cylinder inside a stainless steel can having the external dimensions of a normal core subassembly fuel can. The handling head on the antimony section allows it 


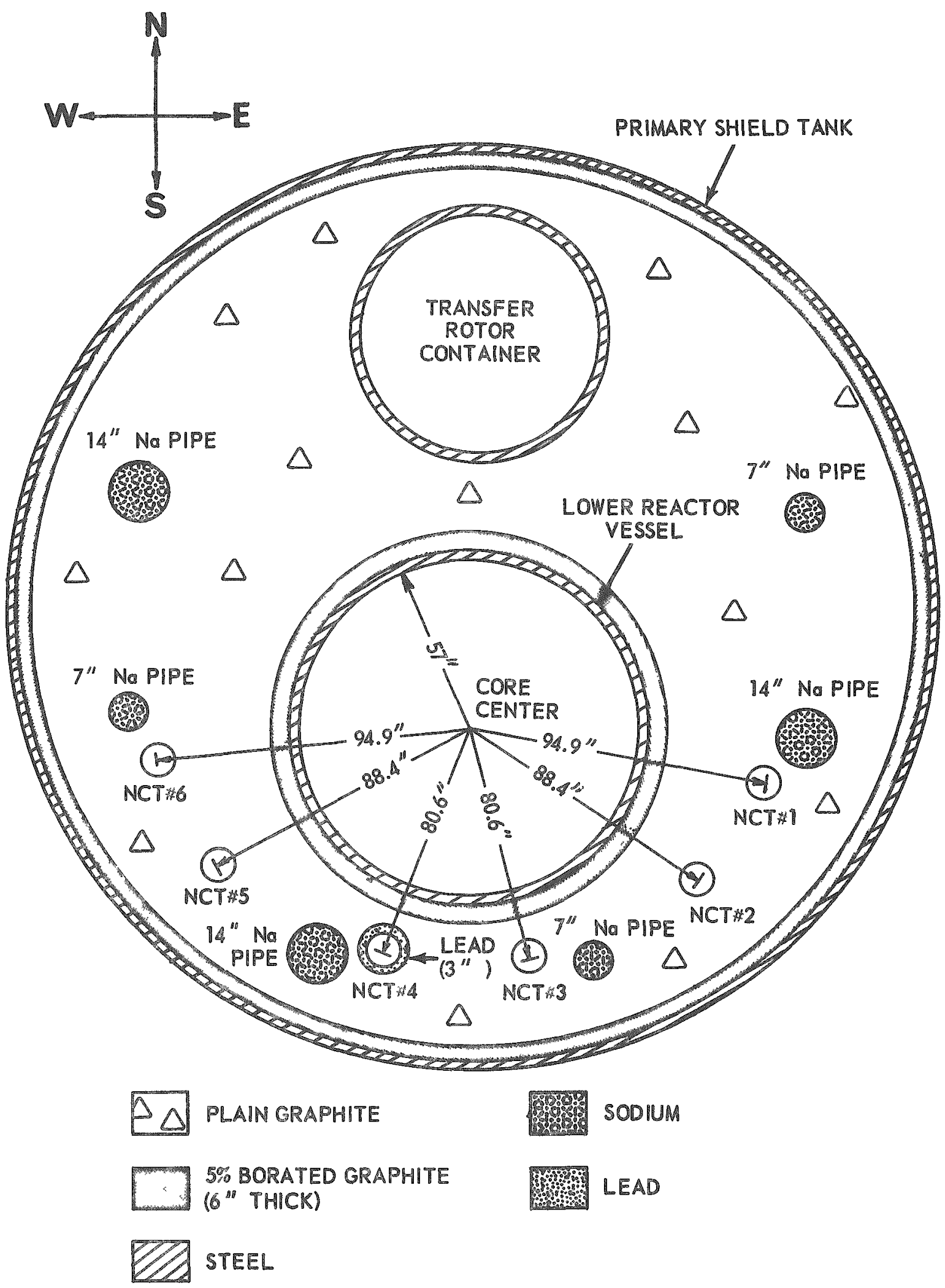

PIG. 3 LOCATION OF NEUTRON-COUNTER TUBES MN GRAPHITE SHIELD 
to be inserted and withdrawn from the beryllium by means of the normal fuel handling mechanism. The beryllium portion must be installed and removed from the reactor through a special access port in the reactor vessel shield plug. 


\section{EXPERIMENTAI PROCEDURE}

\section{A. DESCRIPTION OF THE TEST}

Nuclear fuel was loaded into the core of the Fermi reactor following an extensive period of careful preparation and preoperational testing. The loading was carried out in accordance with a detailed, preplanned program. ${ }^{1}$ The development of the 26-page nuclear test procedure, which was followed during the fuel loading, was initiated more than three years prior to the loading of the reactor. The procedure was revised continually to incorporate improvements and additional steps which would facilitate the acquisition of complete and precise data during the test. In addition, hundreds of individual preoperational tests were conducted on the components and systems of the plant which would be required during fuel loading and reactor operation in the nuclear test program.

\section{Loading to Criticality}

The predicted critical loading of the reactor was based on the results of critical experiment studies conducted on ZPR-III, the fast critical facility at the Argonne National Laboratory. ${ }^{3}$ These studies indicated that a critical mass for Fermi would be achieved with approximately 99 subassemblies in the reactor at a loading temperature of $400 \mathrm{~F}$. 1 Based on this experimental work, it was decided that the reactor would be loaded with 50 fuel subassemblies before initially withdrawing the safety and control rods to establish the subcritical multiplication. The full loading sequence was expected to require approximately ten steps. The initial loading of 50 fuel subassemblies replaced sodium-filled dummy subassemblies at the center of the core. A second loading of 16 subassemblies was scheduled. This was followed by subsequent loadings progressing radially outward into the sodiumfilled annulus formed by the remaining core dummy subassemblies and the already installed depleted uranium radial blanket. By loading in this manner, it was possible to be confident that the negative reactivity of the centrally located safety and control rods was effective.

After each loading step, count rates were obtained from the detector channels at various stages of withdrawal of the safety and control rods. The fuel loading increments beyond the second scheduled loading of 16 fuel subassemblies were determined from the critical mass predictions obtained by linear extrapolation of the rods-up inverse count rate data taken following the completion of each loading. The number of subassemblies which were added in the incremental loadings beyond the second loading was never more than one half the remaining amount of fuel estimated to be required for criticality from extrapolation of the inverse count rate plots. The minimum 
predicted critical mass value was always used to determine the fuel additions. This criterion was followed until the total loading was within two subassemblies of predicted criticality with all rods withdrawn. Subsequent fuel loadings were then in increments of one subassembly until criticality was achieved on withdrawal of the shim and regulating rods.

At all times during the loading of fuel subassemblies, the safety and control rods were located in the core. Prior to and after the loading of each individual subassembly, neutron-detector count rates were obtained on four of the five channels supplying loading data. The fifth channel, an incore absolute fission counter, was not available at this time since it was necessary to retract it to proceed with the handling of the fuel subassemblies. From the data obtained following the loading of each subassembly, a very precise determination was made of the increase in subcritical multiplication with the safety and control rods inserted. Thus, it was possible to follow closely the progress of the loading without withdrawing the safety and control rods at frequent intervals. The extrapolation of the rods-down data indicated that if accurate knowledge of the safety and control rod worth had been available, larger loading increments could have been utilized with fewer rod withdrawals without jeopardizing the safety of the loading to criticality procedure.

While obtaining the subcritical multiplication data after each loading at various stages of safety and control rod withdrawal, data were obtained which permitted an approximate estimate to be made of the safety and control rod worths. Although the rod worths thus obtained were approximate, they demonstrated the adequacy of the reactivity of the safety rods for shutdown purposes and provided an approximate regulating rod calibration curve which subsequently proved to be accurate within \pm 5 per cent.

The Initial Loading-to-Critical Test was scheduled to fully utilize reactor plant time on a 24-hour-day, 7-day-week basis. When possible, nuclear operation (control and safety rod withdrawal) was scheduled for the day shift; and fuel handling and temperature adjustments were made on the evening and night shifts. During the early stages of the loading, the time requixed was controlled by the preparation of the fuel prior to its transfer from the Fuel and Repair Building to the reactor vessel. In the later stages of loading, nuclear operation became the critical time factor because the fuel increments were nominally small when compared to the increased frequency of the periods of nuclear operations. The Nuclear Test Group of Atomic Power Development Associates, Inc. provided 24-hour coverage of the fuel loading and rod withdrawal operations. These personnel monitored and analyzed the neutron count rate data as it was obtained. In addition, consultants were on hand from the Argonne National Laboratory of the Atomic Energy Commission and the Dounreay Fast Reactor Facility of the United Kingdom Atomic Energy Authority at Dounreay, Scotland. 


\section{Flow Dependence Test}

During the later stages of loading to criticality, a test was performed to determine whether any large reactivity effects were associated with changes in primary sodium flow rate. In this test, changes in reactivity due to flow were investigated by observing the subcritical count rate under different flow conditions.

\section{Reactivity Measurements}

Following criticality, various reactivity measurements were made. The measurements included a preliminary calibration of the regulating control rod, edge fuel and inner radial blanket subassembly worths, and the effect of retracting the in-core temporary instrument thimble. The control rod was calibrated by positive-period measurements. The other reactivity worths were obtained by positive-period or critical-rod techniques, or both.

\section{B. NEUTRON SOURCE AND INSTRUMENTATION}

A neutron source was located in the reactor during the test to prom vide an observable neutron flux at the detectors during initial start-up. In addition, in-core and special high-sensitivity out-of-core neutron detectors were installed to assure that large counting rates could be obtained at very low reactor multiplication.

\section{Neutron Source}

Throughout the initial loading, an antimony-beryllium neutron source was located at the core-blanket interface in lattice position N05-N04 (Figure 5).* The source neutrons were multiplied in the fuel by fission as the loading proceeded. The multiplied neutrons were detected by the neutron instrumentation. The neutron source was first placed in the reactor on March 29, 1963. At this time, the reactor vessel was filled with sodium and the core was loaded with dummy core fuel subassemblies surrounded by the depleted uranium radial blanket. The source strength was 1400 curies, with a half life of 60 days, and it produced an estimated photo-neutron yield of $7.0 \times 10^{9} \mathrm{n} / \mathrm{sec}$. When the first core fuel subassembly was placed in the reactor on July 24, 1963, the source strength had decayed to 350 curies. Subsequent decay during the loading period $(\sim 4$ weeks) decreased the source strength to 250 curies at the time of criticality. All subcritical count rates

* The coordinate system which is used to locate subassemblies in the core lattice is shown in Figure 5. The first position number given is the $X-$ coordinate and the second the $Y$-coordinate. "P" stands for positive values and "N" for negative values. The core center is P00-P00. 
obtained during the loading were corrected to the source strength of 350 curies which existed at the start of the loading.

\section{Instrumentation}

The normal plant source range nuclear instrumentation (Section II) could not be used during the approach to criticality because it is of relatively low sensitivity. Therefore, to monitor the low neutron flux levels which existed during the initial stages of the loading, special high-sensitivity neutron detectors were installed. As part of the source range safety system, two high-sensitivity Twentieth Century Electronics, Ltd., BF 3 proportional counters (73 cps $/ \mathrm{nv}_{\mathrm{th}}$ ) were located in the neutron-detector guide tubes to provide both count rate and period signals to the safety system. In addition to these two channels, two high-sensitivity Reuter-Stokes, Inc. BF 3 proportional counters ( $100 \mathrm{cps} / \mathrm{nv}_{\mathrm{th}}$ ) were utilized to provide signals to two monitoring channels. A fifth count rate channel utilized an absolute fission counter, designed and constructed by the Argonne National Laboratory, which contained $199 \mathrm{~g}$. of U-235.4 This detector was positioned at the core midplane in a 2 -inch diameter air-filled temporary instrument thimble which replaced safety rod No. 5 at core position P03-P00 (Figure 5). In addition to the two high-sensitivity $\mathrm{BF}_{3}$ proportional counters in the two source range channels of the safety system, neutron signals to the safety system were provided by five temporary, B-10 lined ion chambers, installed in similar locations in the neutron-detector guide tubes. These detectors supplied both period and power level protection; three of the channels were intermediate range channels and the other two were power range channels. A sixth ion chamber was installed in one of the neutron-counter guide tubes to provide a linear current signal to the operator. When the reactor achieved criticality, this channel provided period information simultaneously with the five count rate channels.

Where possible, the detectors were located at positions of maximum sensitivity to the neutrons originating in the reactor core. During the critical approach, the chief source of information came from the five count rate channels, i.e., the two safety system source range channels, the two monitoring channels and the in-core channel. These channels were referred to as 1 through 4 and $A$, respectively. The locations of Channels 1 through 4 in the neutron-countex tubes during the critical approach are shown in Figure 4. Channels 1,2 and 4 were located in NCT No. 4, and Channel 3 was in NCT No. 3. Both of these counter tubes are symmetrically positioned in the region of highest thermal flux in the graphite shield. As indicated in Figure 4, the 6-inch thick, 5-per cent borated graphite shield layer next to the reactor vessel has plain graphite neutron windows installed opposite NCT Nos. 3 and 4 to further enhance the signal. The sensitivities of Channels 1,2 and 4 were additionally increased by a factor of approximately 4 by surrounding these detectors with layers of polyethylene to a thickness of $1 / 4$ inch. 


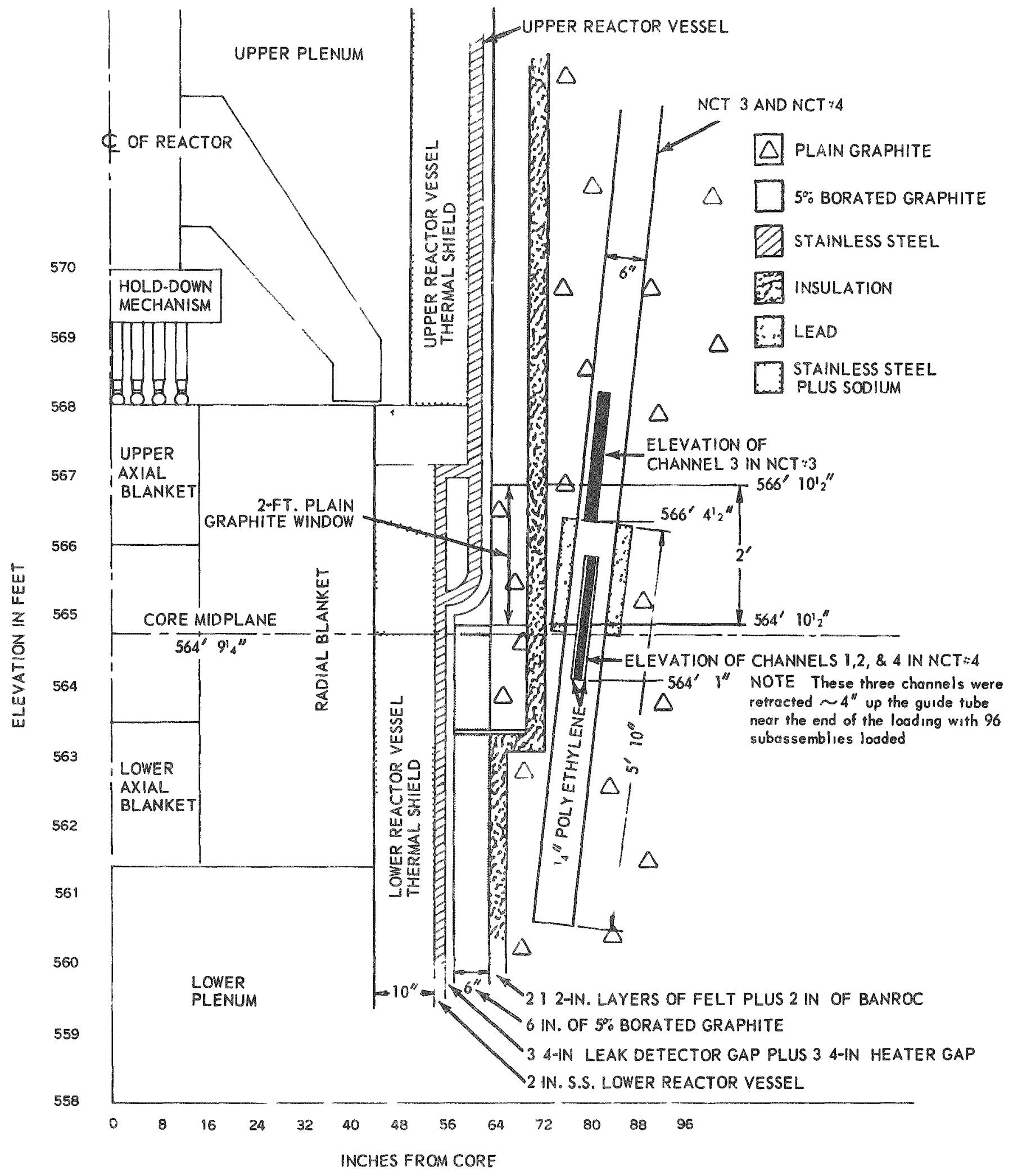

FIG. 4 NEUTRON-COUNTER TUBES NOS. 3 AND 4 , SHOWING THE LOCATION OF THE DETECTORS DURING THE CRITICAL APPROACH 
The temporary staxt-up instrumentation located in the graphite shield, i. e., the four $B F_{3}$ proportional counter channels and the $s i x B-10$ lined ion chamber channels, were nominally room temperature channels rated for a maximum temperature of $175 \mathrm{~F}$. The in-core absolute fission counter channel was designed for operation at temperatures in excess of $500 \mathrm{~F}$. The primary sodium system in the reactor was kept at $400 \mathrm{~F}$ during loading. This resulted in an equilibrium graphite temperature of approximately $250 \mathrm{~F}$ in the vicinity of the out-of-core detectors. Therefore, it was necessary to utilize a specially installed cooling system in the counter tubes to keep these detectors and their associated coaxial cables at temperatures below $175 \mathrm{~F}$. With the cooling system, the temperatures in the counter tubes were kept at approximately $150 \mathrm{~F}$.

Prior to the loading of fuel, the neutron detection instrumentation used for monitoring and safety applications underwent extensive preoperational tests. First, a broad series of programmed preoperational tests were conducted on the detectors and their associated electronics preparatory to inserting them in the reactor. Then, after they were installed in the reactor and the neutron source was placed in the dummy-filled core on March 29, 1963, the detectors were tested again in their operating positions. From these tests, it was determined that the source neutrons were producing a satisfactory signal on the source range proportional counters. The signal at these detectors was three times greater than the signal observed with the source removed. It was thus assured that an adequate knowledge of the neutron multiplication in the reactor, resulting from the loading of fuel, would always be available.

All of the neutron detectors operated satisfactorily throughout the loading to criticality. The five count rate channels which were used to provide information operated reliably and gave consistent data. The five channels were essentially in agreement throughout the loading procedure. The data from Channel 3 did exhibit a minor inconsistency during the early part of the loading; however, because of the relative positions of the detector and source, this was recognized as being due to "source shine", and an appropriate empirical correction factor was applied to the data.

When 93 core fuel subassemblies had been loaded in the reactor, it became necessary to change the gas flow through the in-core absolute fission counter from an argon-nitrogen mixture to pure argon. The change in gas changed the detector characteristic curve sufficiently so that the detector was no longer operating on the plateau. Consequently, it was necessary to make an adjustment in the discriminator setting of this channel. However, this was not made until after the 93 subassembly safety and control rod withdrawal had been completed and, for this reason, the count rate data obtained for this loading requixed an empirical correction factor to maintain continuity of the inverse count rate plots. 
When a total of 96 fuel subas semblles had been loaded in the core and the rods withdrawn, it became apparent that Channels 1,2 and 4 would saturate at the mechanical register $(20 \mathrm{cps}$ maximum) before criticality was reached. Consequently, these three channels were desensitized at this time by moving the detectors to higher elevations in the counter tubes. They were retracted approximately four feet to a region where the thermal flux was about ten times smaller than that which existed at the original positions (Figure 4). Continuity of the inverse count rate data was maintained by obtaining count rates for each channel immediately preceding and following their retraction, with all other conditions held constant. Following the retraction, a second safety and control rod withdrawal was made with this loading as an additional check before more fuel was loaded. 


\section{EXPERIMENTAL RESULTS}

\section{A. THE CRITICAL APPROACH}

Early in July 1963, all preoperational testing of the plant had been completed to satisfaction and number of trial rod withdrawals had been made with no fuel in the core. At this time, however, testing of the temporary fuel loading machine, which had been constructed especially for use during the initial loading in lieu of the cask car, showed that it could not be utilized without modifications in design. Consequently, a two-week delay resulted while the normal plant fuel transfer cask car was prepared for use.

On July 24, 1963, the first core fuel subassembly was loaded into the reactor. Following the initial loading of 50 subassemblies, the safety and control rods were withdrawn for the first time with fuel in the reactor. A similar withdrawal was conducted following the second loading of 16 subassemblies. Subsequent fuel loading increments were determined after each loading from the critical mass predictions obtained by linear extrapolation of the inverse count rate curves. As pointed out in Section III, A. 1, the increments were chosen on the basis that the total number of subassemblies added in the subsequent loading should be no more than one half the minimum estimate of the remaining amount of fuel required for criticality.

\section{Condition of Reactor Prior to the Critical Approach}

Prior to the critical approach, the reactor core region contained dummy sodium-filled, stainless steel filter-type subassemblies (Figure 5). The dummies filled 105 of the 139 available core lattice positions. Of the remaining 34 lattice positions supplied with high pressure sodium, 33 were filled with depleted uranium blanket subassemblies to form an inner radial blanket; the neutron source was located in the remaining position, N05-N04. The outer radial blanket was completely filled with depleted uranium blanket subassemblies, with the exception of the core storage positions at the outer edge of the radial blanket. These were left empty. In addition, the reactor had nine control rods installed, i.e., the shim and regulating rods and seven of the eight safety rods. The No. 5 safety rod position, P03-P00, contained the temporary instrument thimble in which the absolute fission counter was located. Prior to the critical approach, count rates were obtained on the five counting channels with all nine control rods in the fully inserted and fully withdrawn positions. These data were taken on July 23, 1963, the day preceding the first loading of fuel. The source strength at this time was approximately 350 curies of Sb-124. Table I gives the count rate data which were obtained. 
DESCRIPTION

QUANTITY

目 Operating Control Rod

Safery Rod

Temporary Instrument Thimble

[요 Neutron Source

[- Dummy Subassemblies

Inner Radial Blanker Subossemblies

$\square$ Outer Radial Blanket Subossembliss

2

7

1

i

105

33

499

$Y$-COORDINATES

Storoge Postrions

C Thermal Shield Sreel Subassemblies

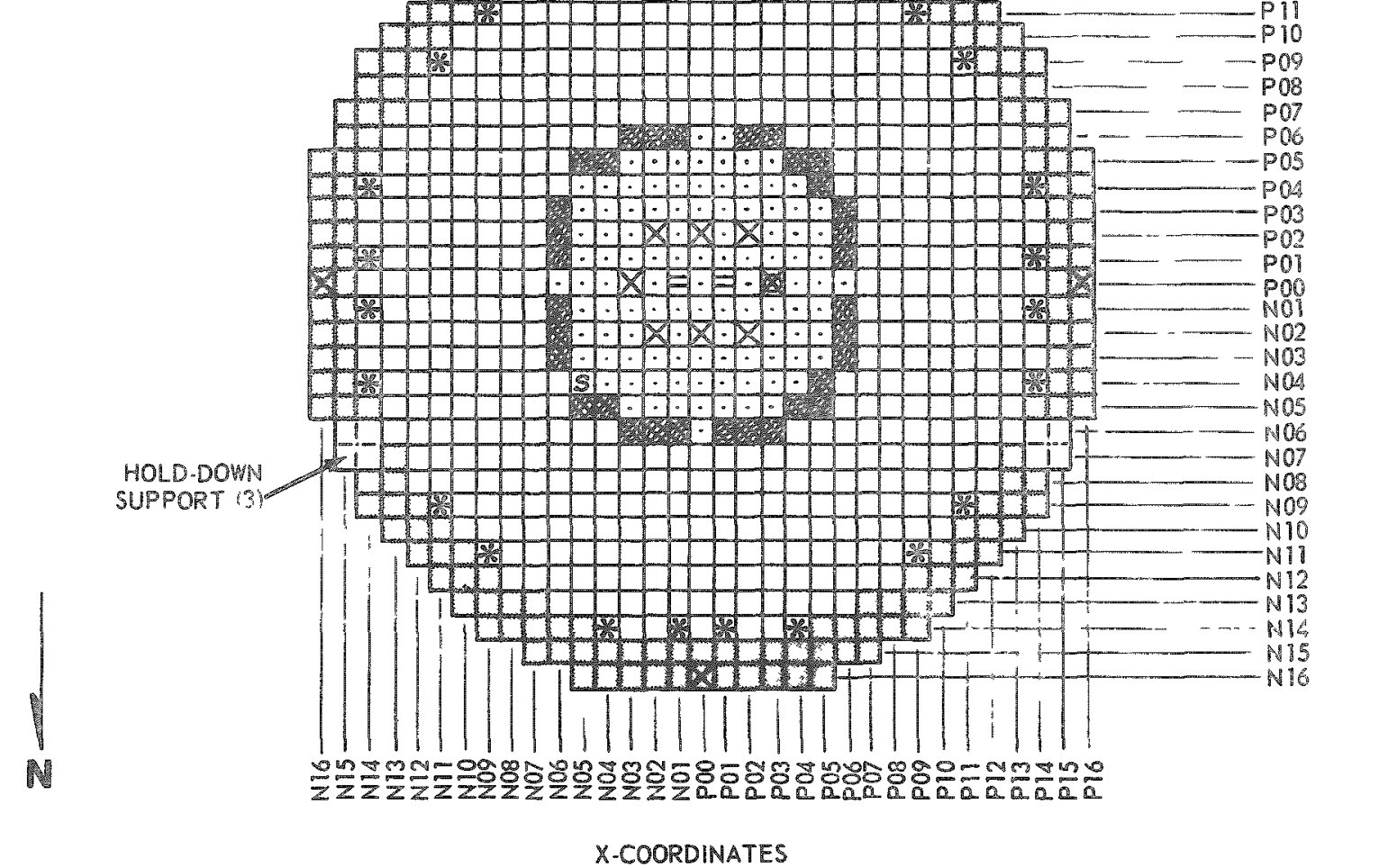




\title{
TABLE I - COUNT RATES PRIOR TO THE CRITICAI APPROACH'
}

\author{
Antimony-124 Activity $\approx 350$ Curies
}

Count Rate (cpm)

Channel $^{\mathrm{b}}$

1

2

3

4

A
All. Rods

Fully Inserted

$47^{\mathrm{C}}$

$52^{\mathrm{c}}$

86

199

28
Ail Rods

Fully Withdrawn

$113^{\mathrm{C}}$

$123^{\mathrm{c}}$

137

462

163

a. Data taken on July 23, 1963, with the detectors located as shown in Figure 4 and the core configuration as shown in Figure 5. Five minute count rates were taken.

b. Channels 1 and 2 were Twentieth Century $B F_{3}$ proportional counters having a sensitivity of approximately $70 \mathrm{cps} / \mathrm{nv}$ th. Channels 3 and 4 were Reuter-Stokes $B_{3}$ proportional counters having a sensitivity of approximately $100 \mathrm{cps} / \mathrm{nvth}$. Channel A was an ANL absolute fission counte $x$ (199 $\mu \mathrm{g}$ of U-235) located in the core at position P03-P00.

c. Due to the scale factor used on the mechanical registers for these two channels, the actual count rate is twice the value given in the table.

The primary system temperature was established at $400 \mathrm{~F}$ isothermal prior to the start of the loading and was maintained at $400 \mathrm{~F}$ during all nuclear operations (rod withdrawals). Temperatures were monitored by use of the normal plant temperature sensing elements. These consisted of thermocouples and resistance temperature detectors. They provided both core inlet and core outlet sodium temperatures as well as support plate and hold-down plate temperatures. The data from these sensors were relayed via special circuits to a temporary, precision temperature readout station located in the reactor control room. Temperatures could be read to an accuracy of $\pm 0.1 \mathrm{~F}$. Graphite temperatures near the neutron-counter tubes were also monitored periodically using the normal plant instrumentation. The reactor temperature was controlled by balancing the heat input from the 
primary sodium pump operation with the heat removal by below-floor ventilation. During nuclear operation, the primary sodium flow was maintained at the rate necessary to establish an equilibrium temperature condition of $400 \mathrm{~F}$ throughout the reactor and primary system. During fuel loading operations, the flow was reduced to either zero or pony-motor flow to prevent the dummy subassemblies from floating.

Safety precautions were taken prior to the test. Included in these precautions were setting the scram trip points of the intermediate power range at a flux level corresponding to $20 \mathrm{kw}$ and setting the trip points of the power range at their minimum level $(\approx 1 \mathrm{Mw})$.

\section{Loading to Criticality}

The first fuel subassembly was deposited in the cort of the reactor replacing a dummy core subassembly at $6: 20 \mathrm{a} . \mathrm{m}$. on Wednesday, July 24, 1963. When the first subassembly was loaded into the reactor, the response of a typical out-of-core neutron detector increased from 47-counts per minute to 68 -counts per minute. Similar increases were observed in the responses of the other detectors. As each additional subassembly was loaded, a further increase in count rate was noted. It had been predicted that the total increase in count rate, with all rods inserted and with the core fully loaded, would be a factor of 420 over that observed from the neutron source alone with no fuel in the reactor. 5 The actual increase in count rate for this condition following criticality was observed to be a factor of 245, which was in satisfactory agreement with prediction.

The first loading consisted of 50 subassemblies located in the central region of the core. On Sunday August 4, 1963, this loading was completed and the safety and control rods were withdrawn for the first time." This provided the first rods-up data for the inverse count $x$ ate curves. Since only one datum point was available, extrapolation to a predicted critical mass could not be made at this time. However, considering that the number of neutrons reaching the detectors with the safety and control rods fully withdrawn was approximately only twice that obtained before withdrawing the rods, it could be conservatively predicted that an additional 16 subassemblies, as called for in the preplanned procedure, could be added to the core in the second loading without achieving criticality. Thus the second loading consisted of 16 subassemblies making a total of 66 subassemblies in the core. After this loading, the rods were again withdrawn and count rate data taken

\footnotetext{
* Although the first loading took place during the period July 24 to August 4 , the actual time required for fuel movement was not this long. A 7-day delay occurred during this time for maintenance on the drive shaft of the fuel storage transfer rotor.
} 
on all channels. With these additional data, the first critical mass prediction could be made from the inverse count rate curves. This determined the size of the third loading. Subsequent loadings were determined in a similar manner.

Table II shows the number of fuel subassemblies which were added in each of the thirteen incremental fuel loadings required to achieve criticality, and the mass of U-235 in the core at the end of each loading. Table II also indicates the minimum number of additional subassemblies which were estimated to be required for criticality with all rods up (zero excess reactivity) after each loading. The estimate was based on linear extrapolation to the zero intercept of the inverse count rate versus loading plots. The number of subassemblies added in the next loading was never more than one-half of this estimated value. Figure 6 shows the location in the core at which each of the subassemblies were added in the arious loadings. Each subassembly contained approximately 4.75 kilograms of U-235."

Subcritical count rates were obtained after each incremental fuel loading at various stages of rod withdrawal. Counts were first taken with all nine control rods fully inserted. The seven ganged safety rods were then withdrawn 15 inches, 33.6 inches (first subcritical stop), 36.2 inches (second subcritical stop), and 54 inches (full out). Following this, the shim rod was fully withdrawn and, lastly, the regulating rod was fully withdrawn. The count rates obtained were always corrected for source decay. Where applicable they were corrected for the "source shine" on Channel 3, the gas change made in Channel $A$, and the retraction of Channels 1,2 and 4 (see Section III, B. 2). Corrected count rates were used to plot the critical approach inverse count rate curves. Table III gives the corrected count rates obtained after each incremental fuel loading for the two limiting cases of rod withdrawal, i.e., with all nine rods fully-inserted and fully-withdrawn. Table IV Iists the source decay factors used to adjust the observed count rates to the source strength of 350 curies which existed on July 23, 1963. The gas correction factor used for Channel A and the "source shine" correction factor which was applied to the Channel 3 data are given in Table V. Table VI lists the detector retraction correction factors which were experimentally determined and applied to the data from Channels 1,2 and 4 for loadings eleven through thirteen.

In an attempt to obtain an early indication of the true critical mass, the corrected count rate versus loading data were plotted using sev-

* The mass of U-235 in the core at the end of each loading listed in Table II is not an exact multiple of the number of subassemblies times 4.75 kilograms because of the tolerance limits on the subassemblies and because some of the subassemblies were special surveillance subassemblies which contained less than the normal amount of $U-235$. 


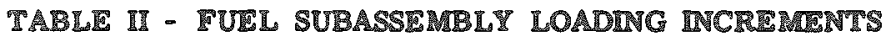

\begin{tabular}{|c|c|c|c|c|c|c|c|c|}
\hline \multicolumn{6}{|c|}{ Loading Desu } & \multicolumn{3}{|c|}{ Nurlear Ileagurement: } \\
\hline 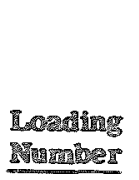 & $\begin{array}{c}\text { Dase } \\
\text { Sarted, } \\
1263 \\
\end{array}$ & $\begin{array}{c}\text { Date } \\
\text { reded, } \\
\text { 1963 } \\
\end{array}$ & $\begin{array}{l}\text { Mumber } \\
\text { of Sub } \\
\text { assembles } \\
\text { Added } \\
\text { In Loading } \\
\end{array}$ & 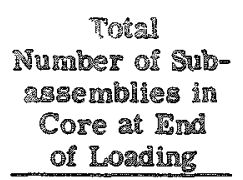 & $\begin{array}{c}\text { Total Klograms of } \\
\text { U-235 in Core at } \\
\text { Ynd of Loading } \\
\end{array}$ & $\begin{array}{c}\text { Date } \\
\text { of Measure ment, } \\
\text { 1973 } \\
\end{array}$ & 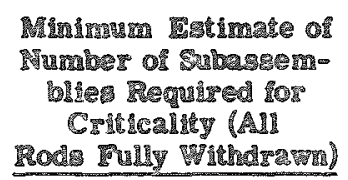 & 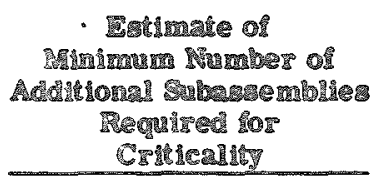 \\
\hline 1 & $7-24$ & $8-4$ & 50 & 50 & 237.68 & $8-B_{3}$ & - & - \\
\hline : & $2-3$ & $9-6$ & 16 & 66 & 313.63 & $8-7$ & 78.6 & 12.8 \\
\hline 3 & $8-9$ & 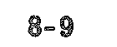 & 6 & 72 & 342. 27 & $8-10$ & 26.3 & 奥 3 \\
\hline 贯 & $8-11$ & $8-11$ & $5^{2}$ & 97 & 366.07 & $8-12$ & 20. & 12.3 \\
\hline 5 & $8-15$ & - 15 & 6 & 23 & 332.57 & $8-15$ & 9. & 露 \\
\hline 6 & $8-16$ & $8-16$ & 迹 & 87 & 418.57 & $8-16$ & 93 & 6.0 \\
\hline 雫 & $8-10$ & $8-17$ & 3 & $\$ 0$ & 427.82 & $8-17$ & 90.0 & 6.0 \\
\hline 2 & $8-17$ & $8-17$ & 3 & 93 & 44.42.18 & $8-18$ & $9 \%$ & s. \\
\hline 8 & $8-18$ & -18 & 2 & 95 & 451.67 & $8-13$ & 97.4 & 2. 술 \\
\hline 10 & $8-19$ & $8-19$ & 1 & 96 & 456.40 & $8-20$ & 97.8 & 1.2 \\
\hline 11 & $8-21$ & -21 & 1 & 97 & 461.14 & $8-21$ & 97.9 & 0.9 \\
\hline 12 & $8-22$ & $8-22$ & 1 & 98 & 465.89 & $8-28$ & $97.0^{b}$ & $b$ \\
\hline 13 & $8-22$ & $8-22$ & 1 & 99 & 470.66 & 8-23 & Criltical $^{\mathrm{C}}$ & - \\
\hline
\end{tabular}

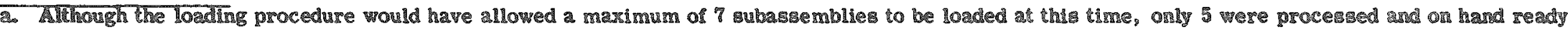
for loading.

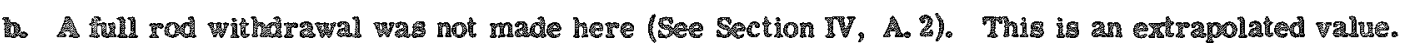

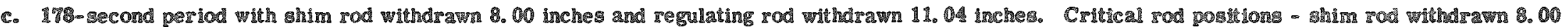

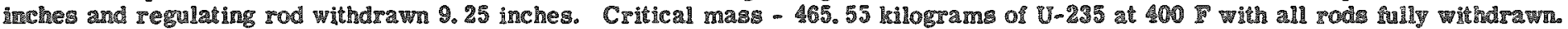




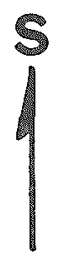

TONCT 23

TO NCT 4

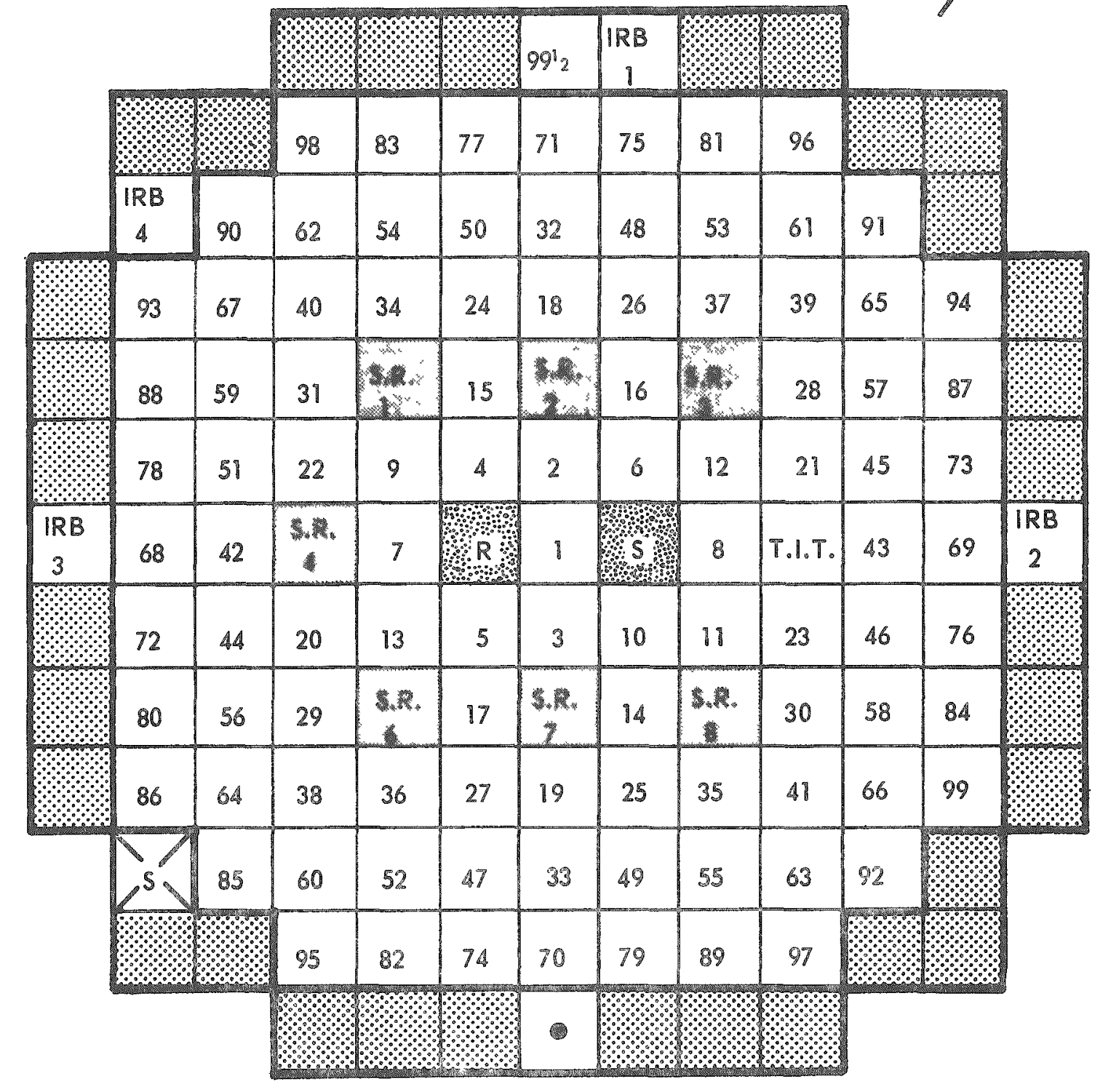

P06

P05

P04

$\mathrm{P} 03$

P02

P01

P00

N01

N02

N03

N04

N05

N06

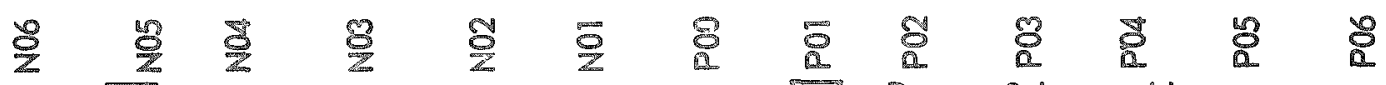

[S] Neutron Source

[0] Durnmy Subassembly

D. Core Fuel Subassembly for Dunury
Substioustion - Numbers $(\mathbb{N})$ indicote subsuence of load ing

Sarisy Rod

[ir] Temporary Instrument Thimble

[and Inner Radial Blanker S.A. for Dummy Subspisution

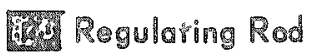

Inner Radial Blanket S.A. in Place

D部 Shis $\operatorname{Rod}$

\author{
Brorere Looding Began
}

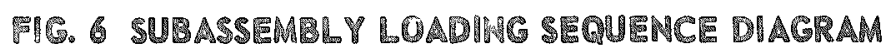


TABLE II - SURCRTICAL MULTPLCATION COUNT RATES

Corrected Conats Per Rinute

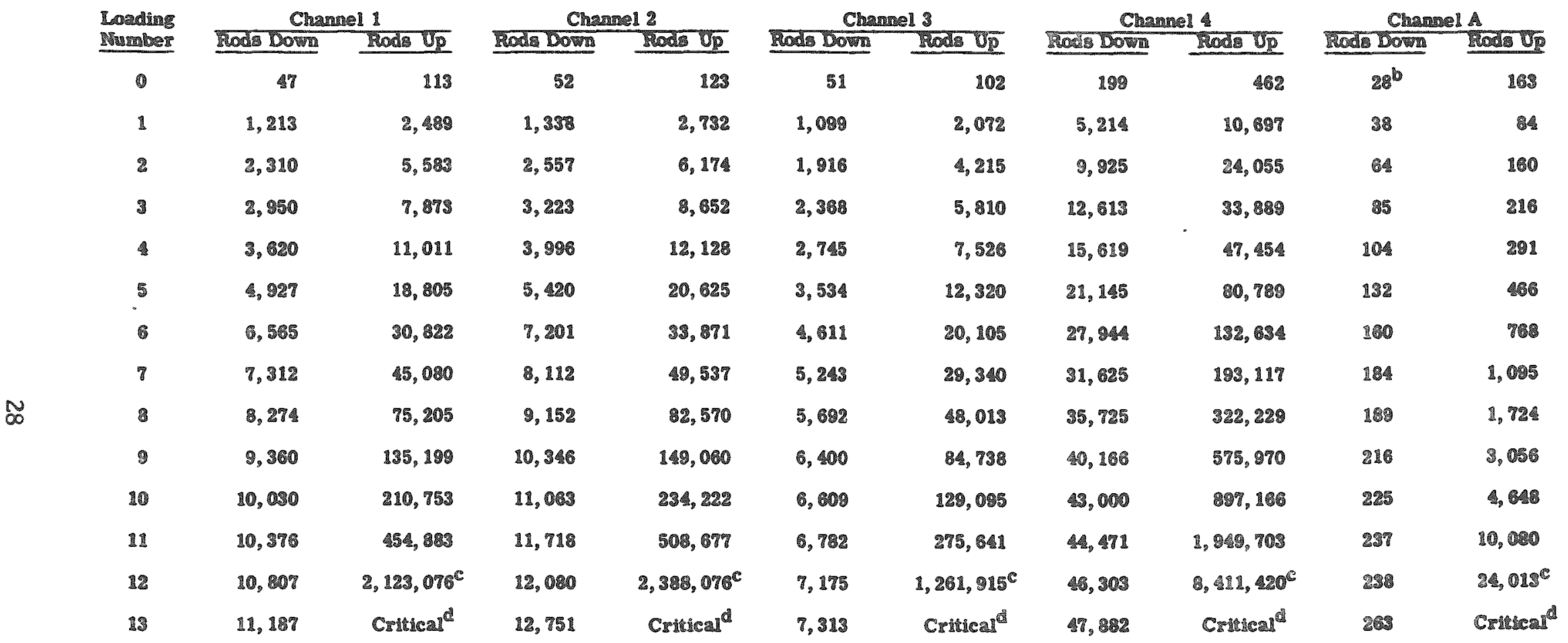

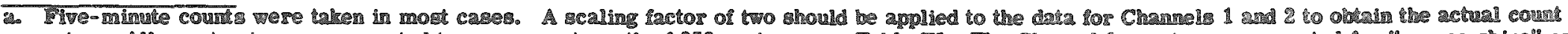

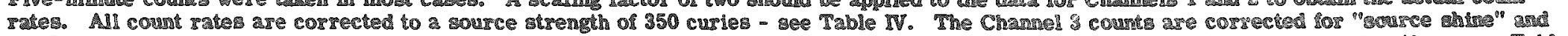

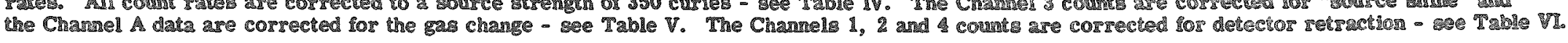

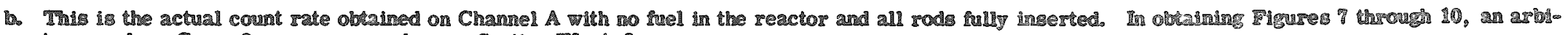
traxy ซalue, $C_{0}=2 \mathrm{cpm}$, was ured - see Section IV, A. 2.

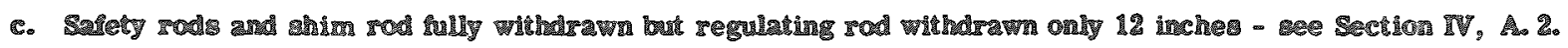

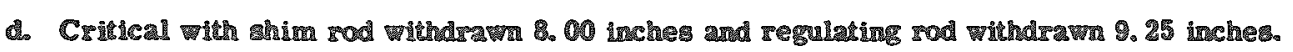




\section{TABLE IV - SOURCE DECAY CORRECTION FACTORS}

$$
\text { Antimony-124 Activity } \sim 350 \text { Curies on July 23, } 1963
$$

\begin{tabular}{|c|c|c|c|}
\hline $\begin{array}{l}\text { Loading } \\
\text { Number } \\
\end{array}$ & $\begin{array}{c}\text { Date of Nuclear } \\
\text { Measurements, } 1963 \\
\end{array}$ & $\begin{array}{c}\text { Source } \\
\text { Decay Factor } \\
\end{array}$ & $\begin{array}{c}\text { Source Decay } \\
\text { Correction Factor } \\
\end{array}$ \\
\hline 0 & July 23 & 1.000 & 1.000 \\
\hline 1 & August 4 & 0.877 & 1.142 \\
\hline 2 & August 7 & 0.846 & 1.182 \\
\hline 3 & August 10 & 0.820 & 1.220 \\
\hline 4 & August 12 & 0.800 & 1.250 \\
\hline 5 & August 15 & 0.774 & 1.292 \\
\hline 6 & August 16 & 0.765 & 1.308 \\
\hline 7 & August 17 & 0.755 & 1.324 \\
\hline 8 & August 18 & 0.747 & 1.339 \\
\hline 9 & August 19 & 0.739 & 1.354 \\
\hline 10 & August 20 & 0.730 & 1.370 \\
\hline 11 & August 21 & 0.719 & 1.390 \\
\hline 12 & August 22 & 0.713 & 1.403 \\
\hline 13 & August 23 & 0.705 & 1.418 \\
\hline
\end{tabular}

a. Antimony -124 half life of 60 days.

b. The subcritical count rates were multiplied by the source decay correction factor for each date to obtain the count rates listed in Table III. 
TABLE V - GAS CORRECTION FACTOR FOR CHANNEL A AND "SOURCE SHINE" CORRECTION FACTOR FOR CHANNEL 3*

\begin{tabular}{|c|c|c|}
\hline Channel & Correction Factor & Application \\
\hline A & 1.24 & $\begin{array}{l}\text { The subcritical cown rates for } \\
\text { Channel A were multiplied by } \\
\text { this correction factor for load- } \\
\text { ing No. } 8 \text { (N = 93) to obtain the } \\
\text { count rates listed in Table III. }\end{array}$ \\
\hline 3 & $35 \mathrm{cpm}$ & $\begin{array}{l}\text { This value was subtracted from } \\
\text { the subcritical count rates for } \\
\text { Channel } 3 \text { to obtain the count } \\
\text { rates listed in Table III. }\end{array}$ \\
\hline
\end{tabular}

* See Section III, B.2 for an explanation of the correction factors.

TABLE VI - NEUTRON DETECTOR RETRACTION CORRECTION FACTORS FOR CHANNELS 1,2 AND $4^{*}$

Channel

1

2

4
All. Rods

Fully Inserted

9.75

10.00

9.86
All Rods Fully Withdrawn

10.00

10.24

10.00

* The subcritical count rates for Channels 1,2 and 4 were multiplied by these correction factors for loadings eleven through thirteen ( $97 \leq N \leq 99$ ) to obtain the count rates listed in Table III. 
eral methods. The curves in Figures 7 through 10 were maintained for each channel throughout the loading and represent the four methods used. They were:

$$
\begin{aligned}
& \text { 1. } C_{O} / C_{N} \text { versus } N \\
& \text { 2. } C_{O} / C_{N} \text { versus } \sqrt{N} \\
& \text { 3. } \sqrt{N} \cdot C_{O} / C_{N} \text { versus } N \\
& \text { 4. } N \cdot C_{O} / C_{N} \text { versus } N
\end{aligned}
$$

where:

$N$ was the number of core fuel subassemblies in the reactor.

$C_{0}$ was the count rate with no fuel in the reactor and all rods fully inserted.

$\mathrm{C}_{\mathrm{N}}$ was the count $r$ ate with $\mathrm{N}$ fuel subassemblies in the reactor at the various stages of rod withdrawal.

As stated above, the four different critical approach curves were plotted to gain an early indication of the critical mass. It was known that the sequence of loading radially outward from the core center, and thus loading fuel at locations of decreasing worth, would result in a conservative critical approach using the standard method of plotting, $C_{O} / C_{\mathbb{N}}$ versus $N$ (Method 1 ). This loading procedure produces curves of the inverse count rate versus loading which are slightly concave, or asymptotic to the zero intercept, thus underestimating the critical mass when using a linear extrapolation to zero. Consequently, plotting Methods 2, 3 and 4 represent attempts to linearize the count rate versus loading data to allow more accurate critical mass extrapolations to be made. These attempts to linearize the data were of little practical value during the initial critical loading because the number of subassemblies loaded was based on the minimum critical loading prediction as outlined in Section II, A.1. The minimum criticalloading prediction was usually obtained from the standard $C_{O} / C_{N}$ versus $N$ plot. Consequently, the other methods were investigated mainly for possible use in future loadings where a less conservative loading procedure might be followed.

The various plots for the ive counting channels are shown in Figures 7 through 10. In these figures, the data with all of the rods fully inserted and fully withdrawn are the only data given. However, the actual working curves maintained throughout the loading included the data obtained at the other rod withdrawal positions. In Figures 7 through 10 , the data for Channels 1, 2 and 4 were averaged and plotted as one curve because the data are essentially indistinguishable on an individual basis. The rods-down data 


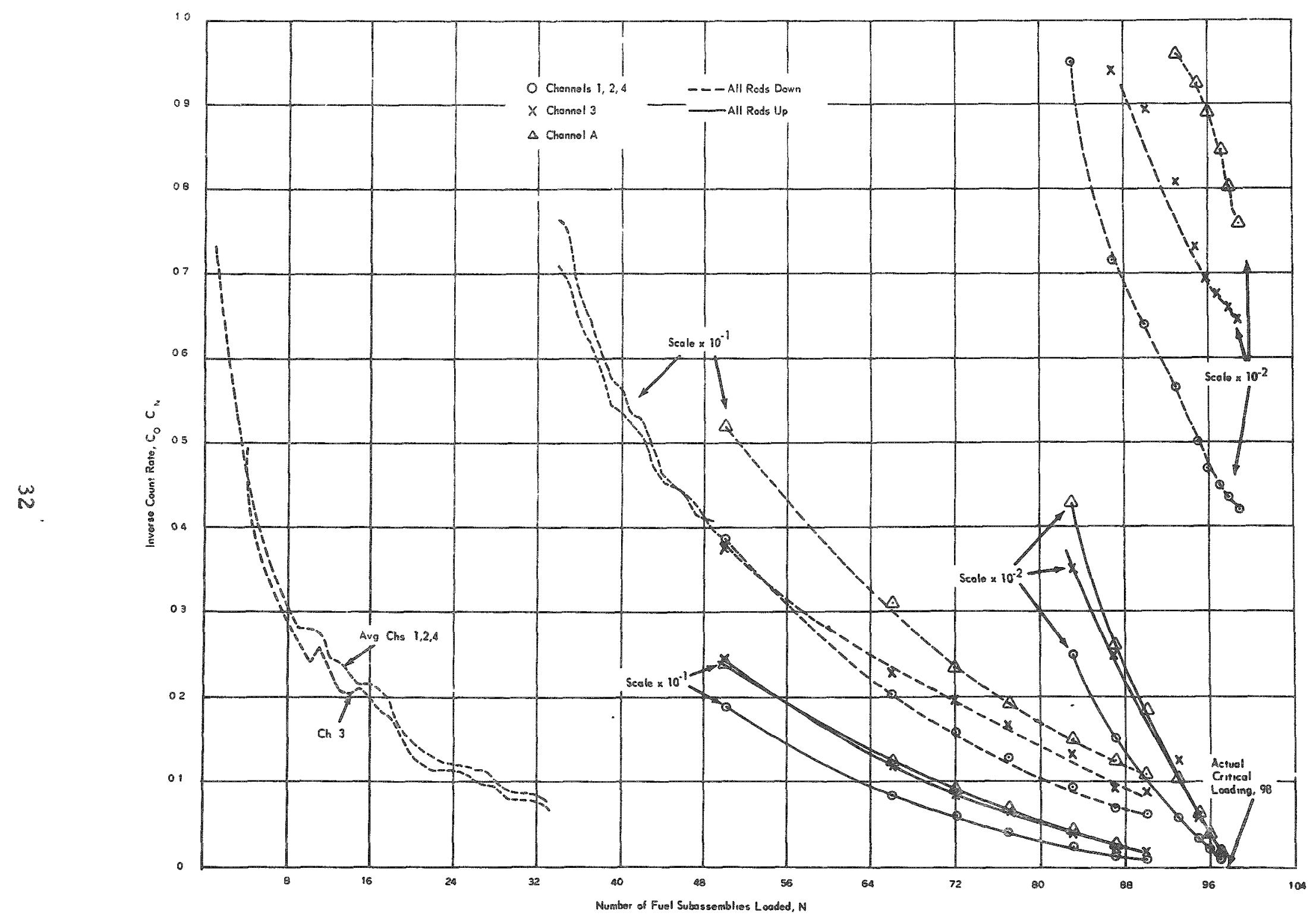

FIG. 7 INVERSE COUNT RATE VERSUS LOADING CURVES $-C_{D} / C_{N}$ VS $N$ 


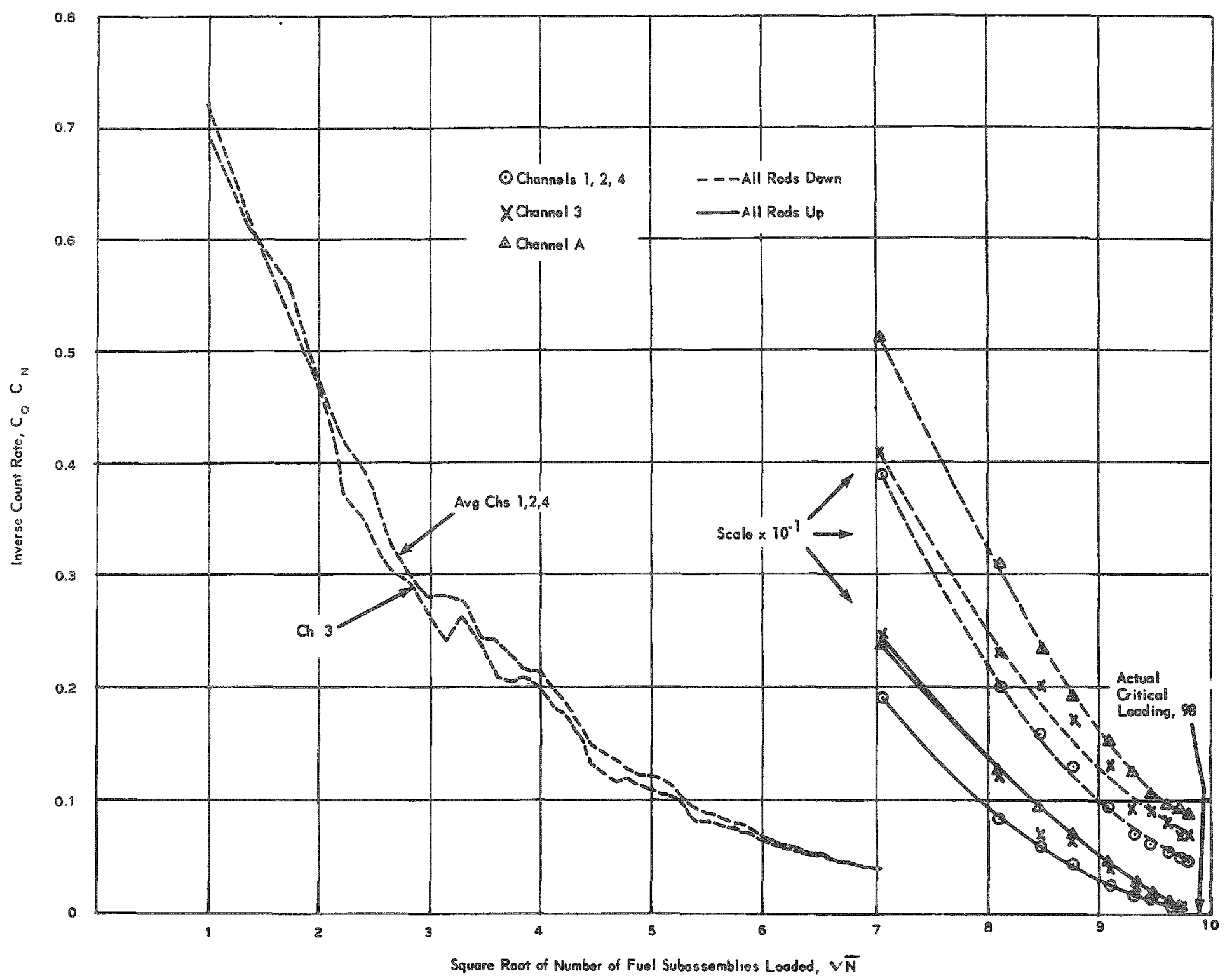

FIG. 8 INVERSE COUNT RATE VERSUS LOADING CURVES $-C_{0} / C_{N}$ VS $\sqrt{N}$ 



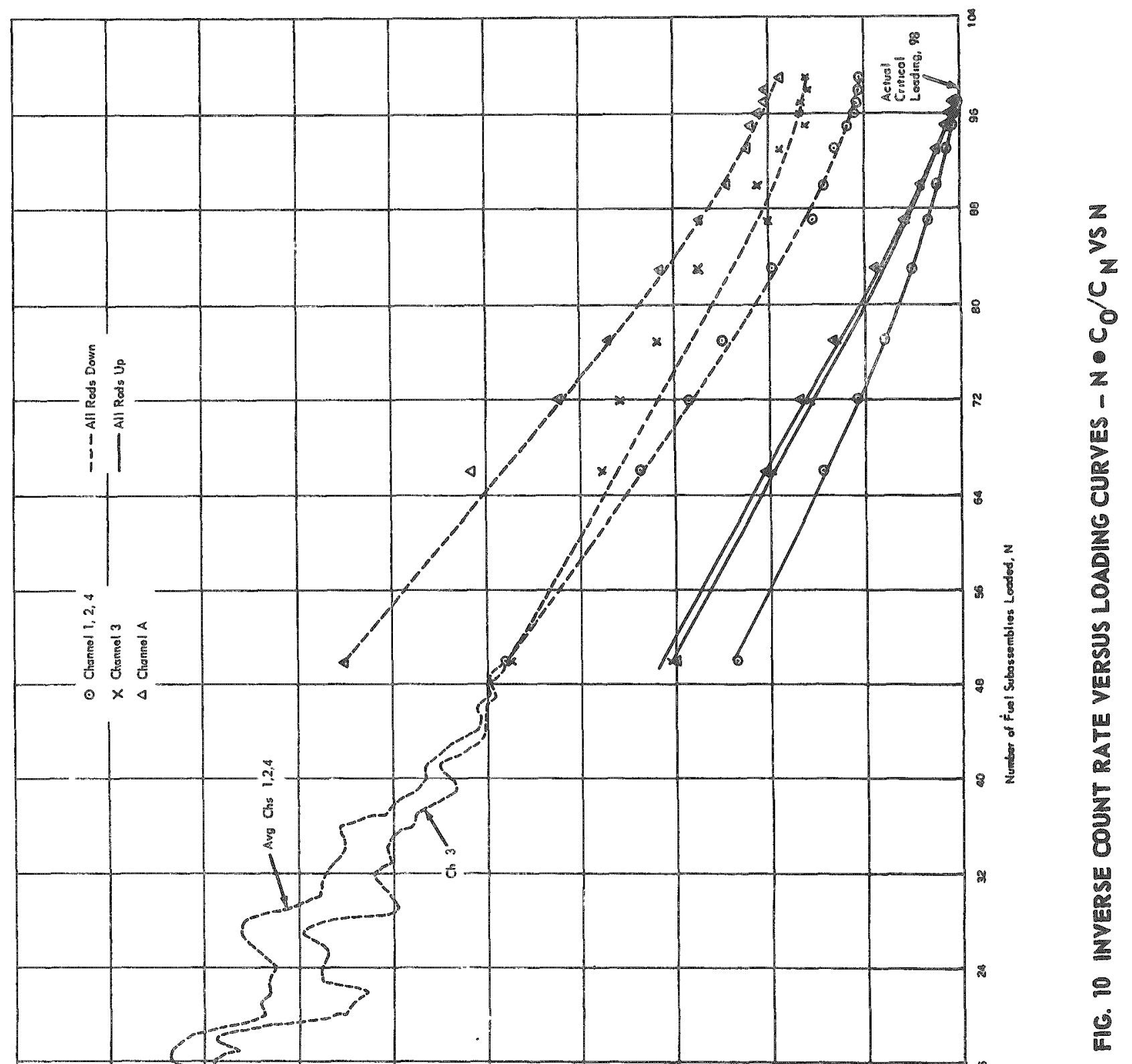


for Channels 1 through 4 for $0 \leq N \leq 50$ (the first loading) were obtained after each individual subassembly was loaded with the safety and control rods delatched and fully inserted in the core. Similar data were not obtained for the in-core Channel A since the temporary instrument thimble had to be retracted during the fuel loading operations. Therefore, the data for Channel A begin at $N=50$, the time at which the rods were first withdrawn. For computation purposes, the Channel $\Lambda$ count rate with no fuel in the reactor and all rods fully inserted, $C_{O}$, was arbitrarily set equal to $2 \mathrm{cpm}$. In the case of the other four channels, the $C_{0}$ values used were thosc actually determined experimentally prior to the loading (Table I) * It will be noted in the figures, thai no data are plotted for the case of the control rods fully withdrawn and $\mathrm{N}=98$. These data were not obtained. With this loading, the reactor would have been slightly supercritical ( 1 to 2 cents) with all the rods fully withdrawn. Therefore it was decided not to fully withdraw the rods at this time because it would have been difficult to determine criticality under these conditions of low excess reactivity. Instead, the reactor was shut down and another subassembly loaded so that criticality could be demonstrated by means of a reasonable positive period.

As seen in Figures 8 through 10 , none of the attempts to obtain a linear critical approach plot were very successful. However, the curve obtained using plotting Method 4 was more linear than the others. The graphical representation which actually gave the best early indication of the true critical mass is shown in Figure 11. In this figure, the ratio of the count rate is obtained with all rods down, $C_{D}$, to that obtained with all rods up, $C_{U}$, is plotted as a function of the loading, i.e., $C_{D} / C_{U}$ versus $N$. As seen, this curve is convex rather than concave, and a smooth curve drawn through the points obtained at an early stage of the loading would extrapolate very close to the final critical value. However, Figure 11 was not used to make official predictions during the loading because a linear extrapolation of a convex curve results in an overestimation of the critical mass, and therefore is not conservative.

The critical mass predictions obtained from the five channels after each loading by the four methods of plotting are given in Table VII. It should be noted that all channels were in close agreement throughout the approach to criticality. The different methods indicated quite a bit of spread early in the approach, but as the loading proceeded they came into closer agreement. Near the end of the approach, all methods of plotting gave the same critical prediction within the limits of experimental error. These results are illustrated in Figures 12,13 and 14 . The asymptotic trend of the data towards the final critical value is clearly evident in these figures.

* The $C_{0}$ value for Channel $A$ was arbitrarily set equal to 2 cpm to obtain inverse count rate plots of the same order of magnitude as those of the other four channels. The actual $C_{0}$ value for Channel $A$, given in $T a b l e I$, 


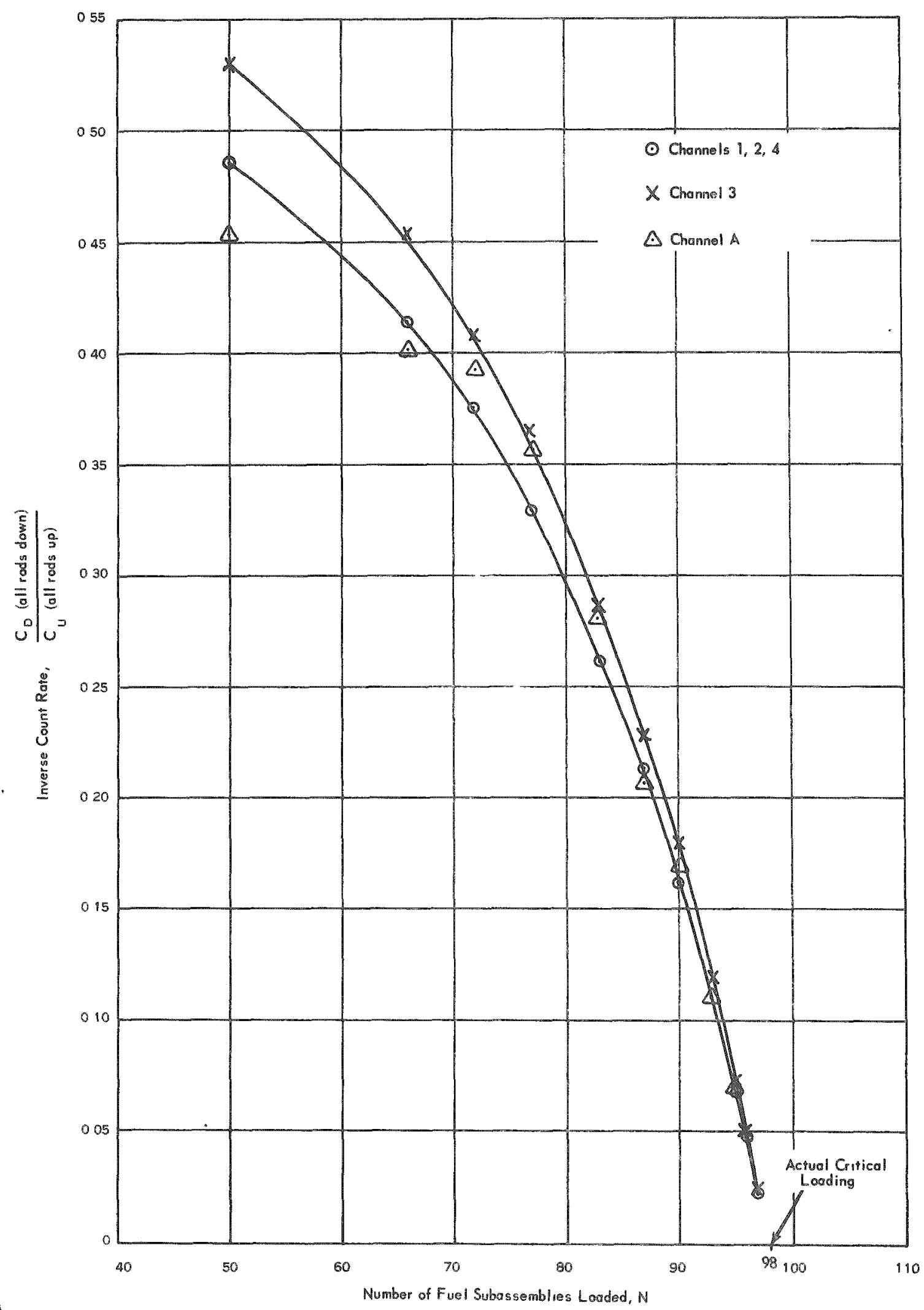

FIG. II INVERSE COUNT RATE VERSUS LOADING CURVES $-C_{D} / C_{U}$ VS N 


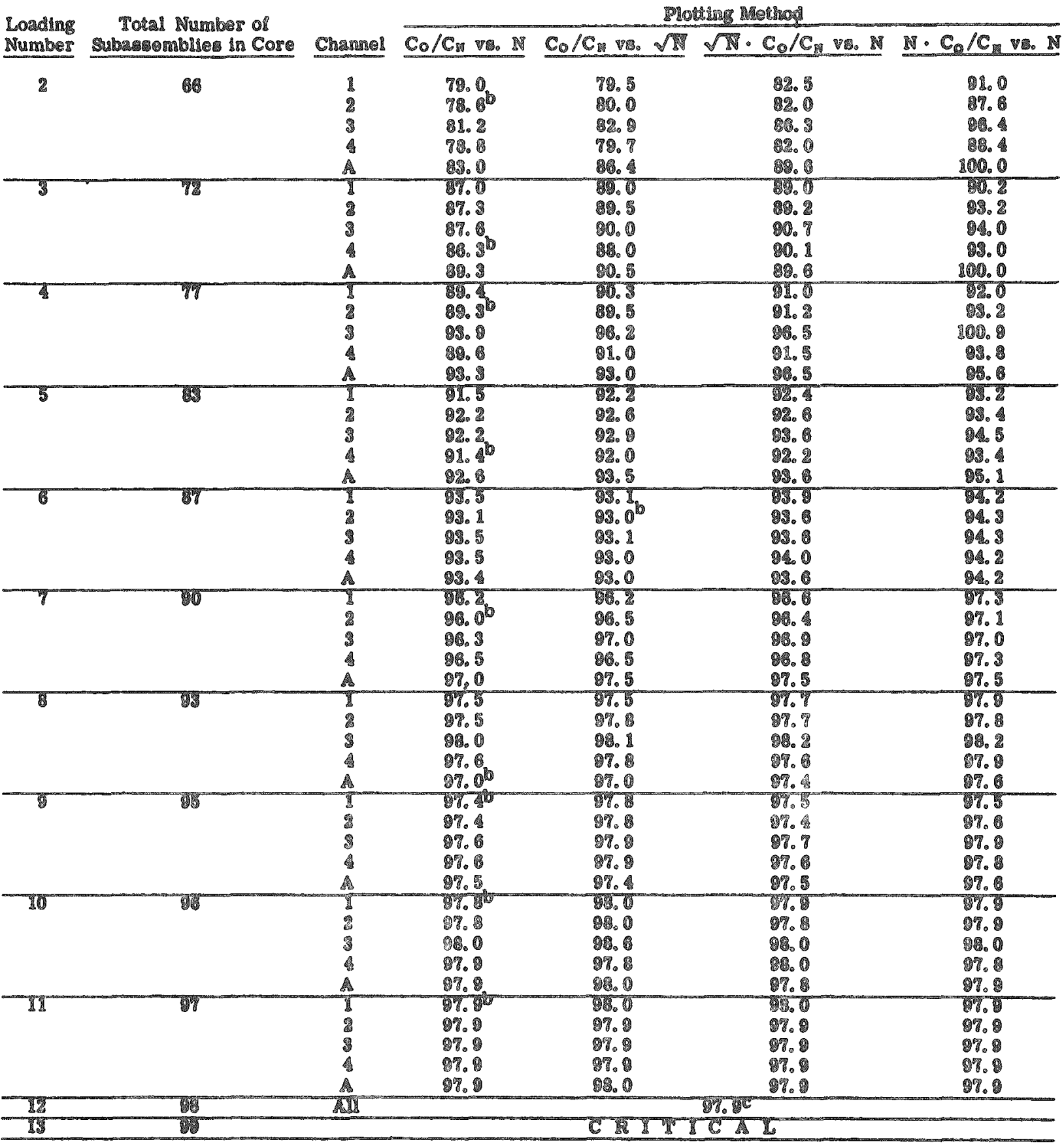

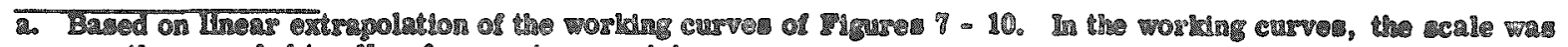

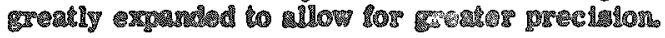

b. Mamimam predeted volne.

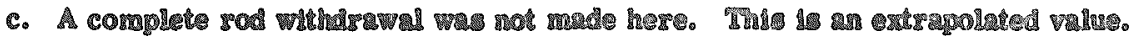




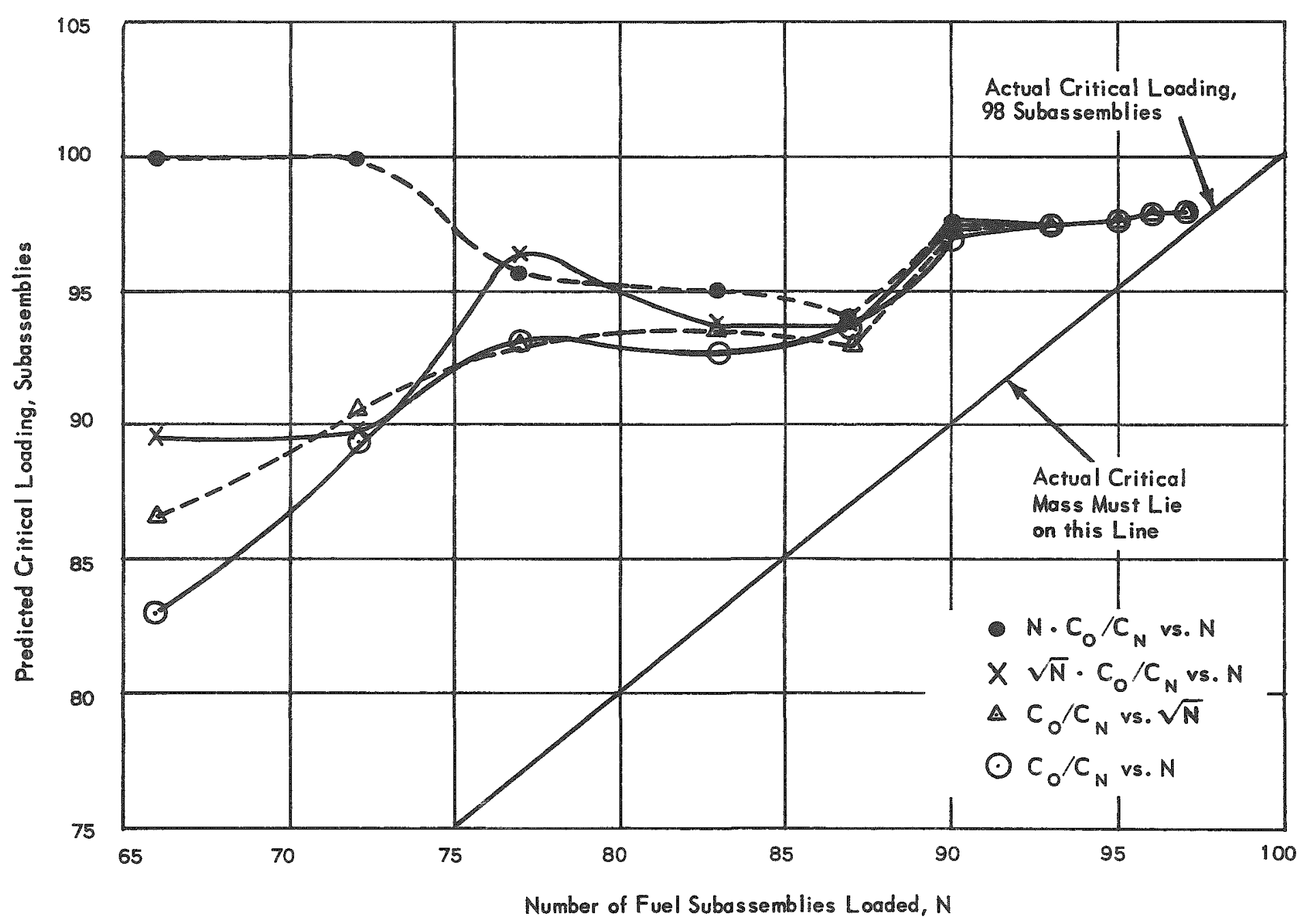

FIG. 12 PREDICTED CRITICAL LOADING VERSUS LOADING CURVES FOR CHAMNEL A 


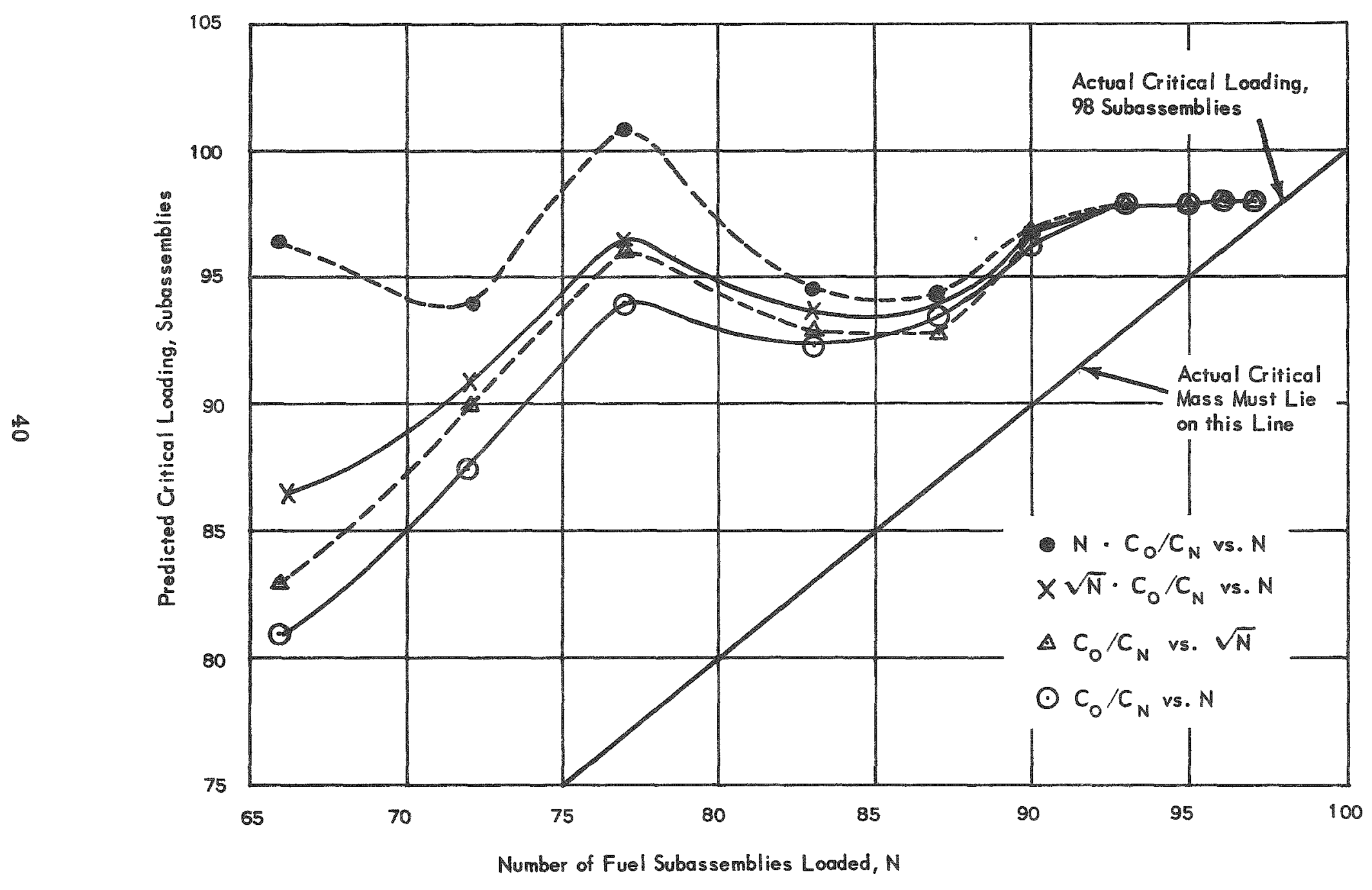

FIG. I3 PREDICTED CRITICAL LOADING VERSUS LOADING CURVES FOR CHANMEL 3 
05

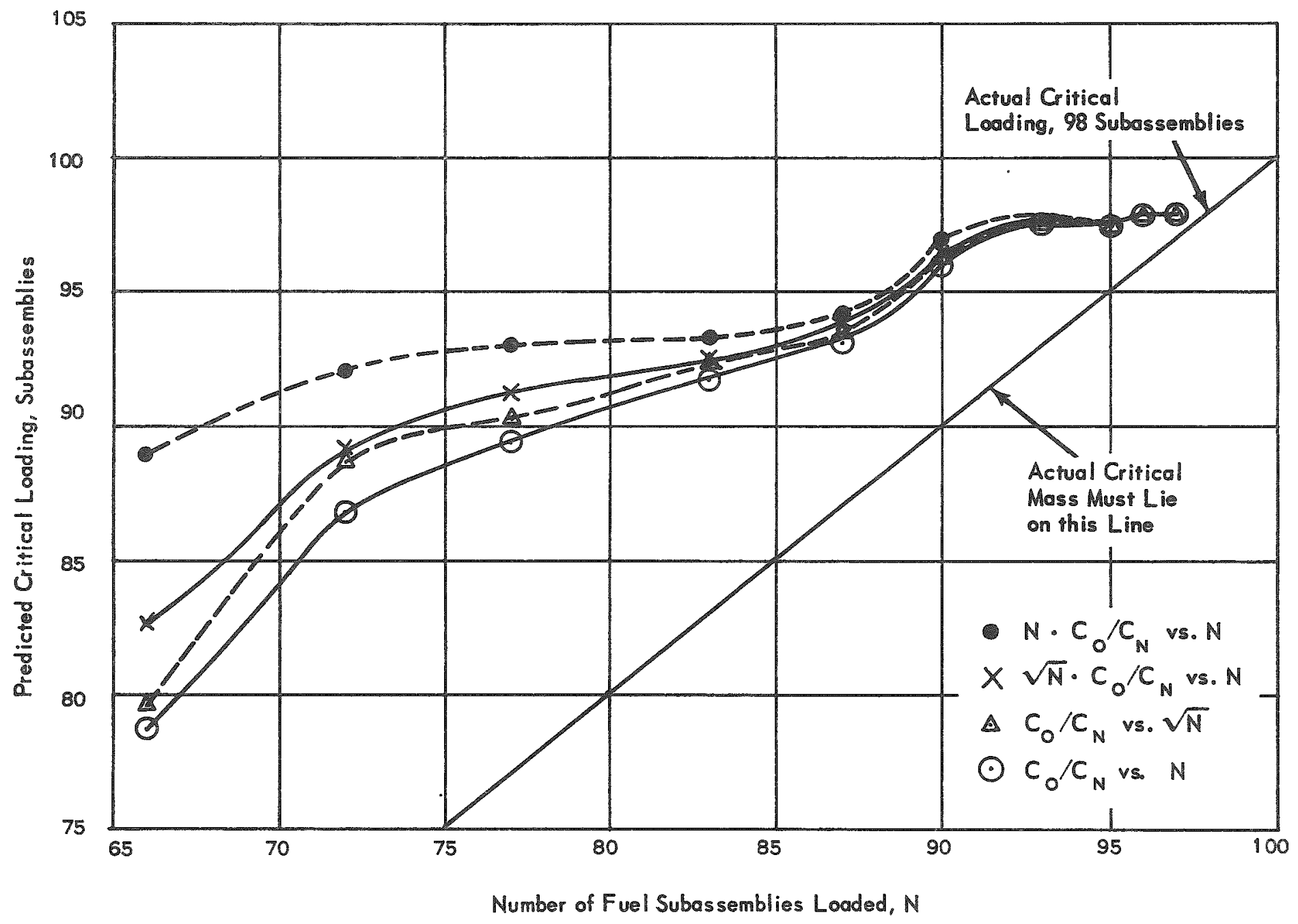

PIG. IA PREDICTED CRITICAL LOADMG VERSUS LOADING CURVES FOR CHANMELS I. 2 AND 4 


\begin{abstract}
* Footnote (continued):
was $28 \mathrm{cpm}$. However, as seen in Table III, the Channel A count rate with all the rods down and $N=50$ increased to only $38 \mathrm{cpm}$. The corresponding increases on the four out-of-core channels were much larger (Table III). Therefore, an arbitrary $C_{0}$ normalization of $2 \mathrm{cpm}$ was used to make the $N=50$ data point for the Channel A inverse count rate curves of the same magnitude as those of the other channels.
\end{abstract}

Spectrum effects are the probable explanation for the difference seen between the count rate increase of the in-core and out-of-core channels fol lowing the loading of the first 50 subassemblies. With no fuel in the reactor a relatively soft $27 \mathrm{kev}$ Sb-Be source neutron core spectrum had existed. As fuel was loaded radially outward from the core center, the neutron spectrum in the core was hardened because of the source multiplication by fission in the fuel. In the case of the in-core detector, this spectrum hardening caused a decrease in the counting probability for neutrons entering the detector. This tended to offset the increase in source multiplication resulting from fuel loading and probably accounts for the small increase in count rate observed on this channel during the loading of the first 50 subassemblies.

A similar spectrum effect did not occur at the location of the out-of-core detectors because the neutron flux at these detectors was due to the leakage of neutrons created by fission in the radial blanket. In this case, an equilibrium spectrum existed at the out-of-core detectors which was essentially independent of the energy of the core neutrons. However, the hardening of the core spectrum did effect the out-of-core detector response in another way. It caused an increase in the relative number of U-238 fast fissions in the blanket and therefore tended to increase the out-of-core detector response. Consequently, whereas core spectrum hardening tended to offset the source multiplication increase seen by the in-core channel, it had the opposite effect on the out-of-core channels. This would explain the difference in the count rate increases obtained following the loading of the first 50 subassemblies. For practical purposes, the core spectrum had also attained equilibrium by the time 50 abassemblies had been loaded. This explains the fact that the in-core and out-of-core channel plots were in good agreement from this point through the remainder of the loading.

\title{
3. Determination of Cricical Mass
}

At 12:23 P.M. on Friday August 23, 1963, the reactor was brought to criticality with 99 subassemblies in the core. The reactor was initially taken to a power level of approximately $1 \mathrm{kw}$ on a 178 -second period with the shim rod withdrawn 8.00 inches and regulating rod withdrawn 11.04 
inches. The subcritical measurements made prior to criticality indicated that a period of 180 seconds would be achieved with these rod positions. The critical rod positions were determined to be 8.00 inches on the shim rod and 9.25 inches on the regulating rod. The reactor temperature was isothermal at $402 \mathrm{~F}$. Based on the preliminary regulating rod calibration obtained in this test (Section IV, B. 1) and the temperature coefficient of reactivity measurements made later in the test program, it was determined that the core loading of 99 subassemblies shown in Figure 6 contained 121.0 inhours of excess reactivity at $400 \mathrm{~F}$ with all control rods fully withdrawn. The replacement worth of a fuel subassembly for a dummy at the core edge was also measured in this test (Section IV, B. 4). Based on its value of 113.5 inhours, it was concluded that the critical loading of the reactor was 97.93 subassemblies at 400 F for zero excess reactivity. From the loading data in Table II, it was concluded that the clean critical mass of the reactor at $400 \mathrm{~F}$ was $465.55 \mathrm{kilograms}$ of $\mathrm{U}-235$. The predicted value was 467.88 kilograms of $U-235.1$ The clean critical mass value would change slightly if the reactivity effects of the temporary instrument thimble in position $\mathrm{P} 03-\mathrm{P} 00$, the source in N05-N04, and the six dummy subassemblies left remaining in the inner radial blanket were taken into consideration.

\section{B. REACTIVITY EFFECTS}

Various preliminary reactivity worth measurements were made during the test. They were done at this time because of their importance to the subsequent tests. The reactivity determinations were made by critical rod position measurements and/or positive-period measurements, except in the case of the flow effect investigations which were conducted subcritically. The critical rod and period methods of measuring reactivity were in excellent agreement in all cases after the data were corrected for temperature and flux drift. In all instances, the agreement between predicted values and expeximental values were excellent. The results of these reactivity measurements are summarized in Table VIIJ.

\section{Control Rod Calibrations}

Shortly after initial criticality, positive-period measurements were made to obtain a preliminary calibration of the regulating rod worth as a function of position. The result of this calibration is shown in Figure 15. The reactivity conversion factors for the Fermi reactor are as follows:

$$
\begin{aligned}
& 1 \text { cent }=3.19 \text { inhours }{ }^{2} \\
& 1 \text { inhour }=2.08 \times 10^{-5} \Delta \mathrm{k} / \mathrm{k} \\
& \beta_{\text {eff }}=0.00662 .
\end{aligned}
$$

* Isothermal temperature coefficient at $400 \mathrm{~F}=-0.87$ inhour per degree $F$. 


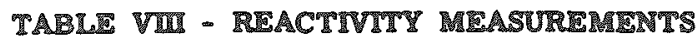

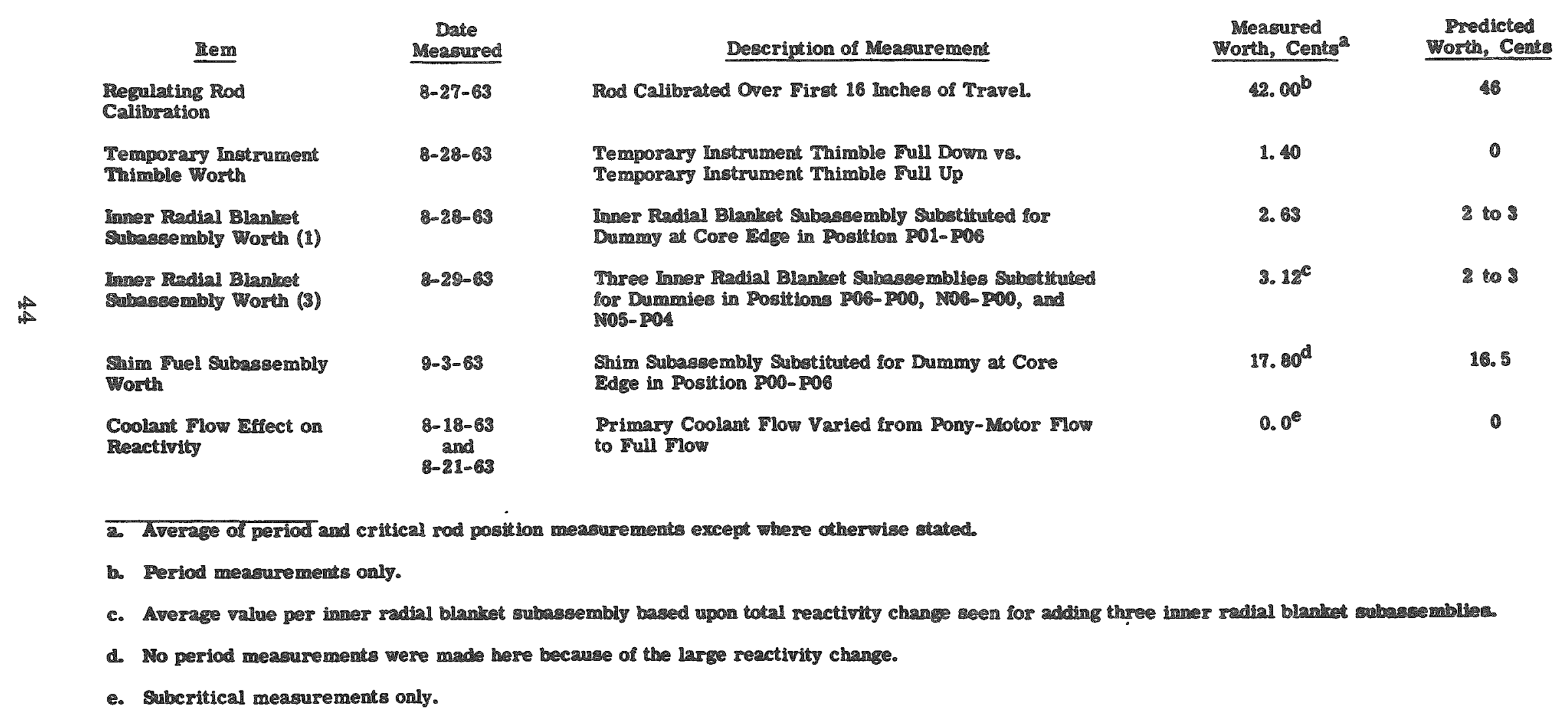




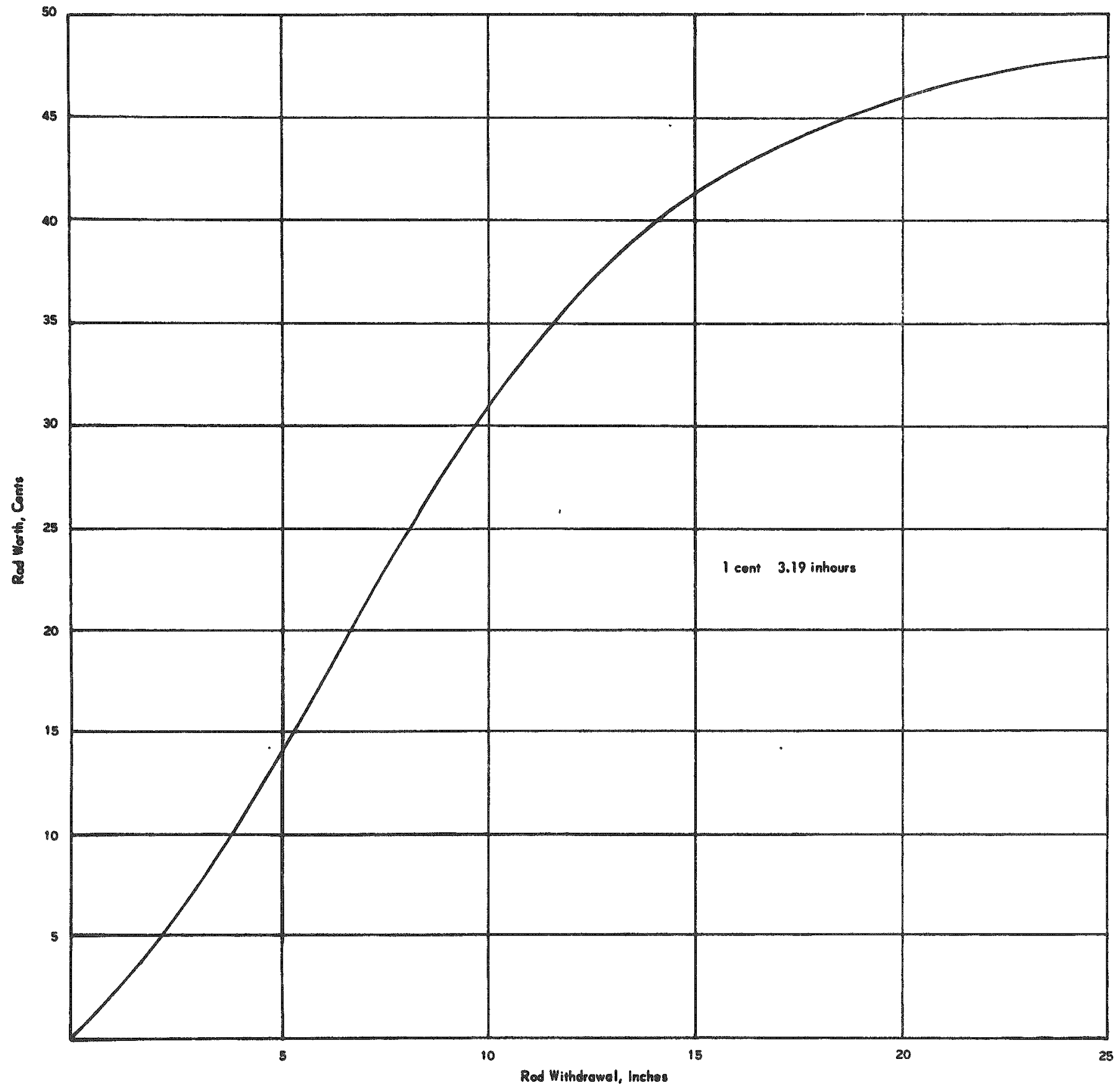

FIG. 15 regculating rod CALIBRATION CURVE 
An approximate regulating rod calibration was obtained by subcritical methods during the course of the loading. It agreed to within 5 percent with the calibration shown in Figure 15. Although the shim rod was not calibrated in this test, its calibration was assumed to be the same as that of the regulating rod since both rods are located at symmetrical positions in the core lattice (Figure 2), and both contain the same quantity of B-10 poison material, 87 gms/ $r o d$, in the form of 34 -per cent enriched $\mathrm{B}_{4} \mathrm{C}^{2} 2$

The positive-period calibration of the regulating rod over its full length of travel was made without any excess reactivity adjustments in the reactor. Therefore, various degrees of shim rod shadowing conditions existed throughout the course of the calibration. In particular, the regulating rod was fully shadowed by the shim rod during the calibration of its upper range of travel, partially shadowed in its middle range of travel, and completely unshadowed when the lower range of its worth curve was obtained. The calibration obtained in this way gave a total regulating rod worth of 42 cents for the first 16 inches of rod withdrawal. The predicted value, based on the Core A critical experiment, was 46 cents. ${ }^{2}$ The 9 -per cent difference is thought to have resulted from design changes which were made subsequent to the critical experiment. 6

Although no attempt was made to obtain a calibration of the safety rods in this test, an approximate estimate of the ganged safety rod worth was obtained by observing the change in subcritical count rate which occurred when the safety rods were withdrawn during the course of the loading. The ganged safety rod negative reactivity worth thus obtained was approximately 12 dollars for the seven rods. This is estimated to be about 50-per cent larger than their actual worth. Nevertheless, the measurements provided adequate assurance that the rods contained sufficient shutdown reactivity.

There was another point of interest concerning rod worth predictions investigated in this test. If the inverse count rate curves (Figures 7 through 10) for rods-up and rods-down are extrapolated to their respective zero intercepts (predicted critical loadings), then theoretically the difference in the number of edge fuel subassemblies required for criticality in each case should be a measure of the rod worth, expressed in units of edge subas semblies.

Using the method outlined above, and assuming the worth of an average edge subassembly to be approximately 33 cents with respect to sodi$\mathrm{un}_{9}{ }^{3}$ the inverse count rate critical approach curves were analyzed for both operating control rod worth and safety rod worth periodically throughout the loading to critical." The results, however, were inconsistent and in poor

* Figures 7 through 10 cannot be used for this analysis because they contain only the all-rods-down and all-rods-up data. The actual working curves were used which contained the intermediate rod withdrawal data. 
agreement with the predicted rod worth values. The results obtained are shown in Table IX. It was thought that the method would give more accurate rod worth values near the end of the loading than it did. The conclusion reached was that this method of determining rod worth had a rather large degree of inherent error due to the changing slopes of the rods-down and rods-up inverse count rate curves.

\section{Worth of the Temporary Instrument Thimble}

The temporary instrument thimble, which was located in the core in safety rod position No. 5 (P03-P00), could be withdrawn from the core when desired. The thimble contained the absolute fission counter and an aluminum filler plug, located in the core region. The thimble was designed so that a zero reactivity effect would result when it was retracted and replaced by sodium. To verify this, and to further establish that no salety hazard would exist if the thimble were retracted while the reactor was operating, a test was conducted to determine the reactivity change resulting from thimble retraction. It was found that a slight reduction in reactivity, -1.4 cents, occurred upon retraction of the thimble.

\section{Worth of a Shim Fuel Subassembly at the Core Edge}

Special reactivity shimming fuel subassemblies are available which contain approximately one-half enriched and one-half depleted uranium fuel pins. These are called shim fuel subassemblies and are intended for use when a finer reactivity adjustment is desired than could be achieved with a normal core subassembly.

After initial criticality, it was necessary to make a small increase in the excess reactivity loading of the reactor prior to further testing. To do this, a shim subassembly was added in place of a dunmy subassembly in core lattice position P00-P06 (Figure 6). Reactivity measurements were taken before and after its insertion. From these measurements, a positive worth of 17.8 cents $(57 \mathrm{ih})$ was found for the shim subassembly at the core edge. Therefore, the normal core subassembly replacement worth would be approximately double this value, or 35.6 cents $(114 \mathrm{ih})$. This is slightly larger than the predicted value of 33 cents. ${ }^{3}$

4. Replacement Worth of Inner Radial Blanket Subassemblies for Dummies

Prior to the critical approach, the 139 core lattice positions contained 105 dummy subassemblies, 33 inner radial blanket (IRB) subassemblies, and the neutron source subassembly. After the reactivity shimming outlined above was completed, 100 of the original 105 dummy positions were filled, thus leaving five which still contained dummies. Four of the se positions were filled with IRB subassemblies to complete the inner radial blanket. 
TABLE TE - ROD WORTIS OBTAIIED FROM FITRAMOLATIONS OF ROOS-UP, RODS-DOWN DATA

Extrapolated Rod Worth, Dollara

\begin{tabular}{|c|c|c|c|c|c|c|c|c|c|}
\hline \multirow[b]{4}{*}{ 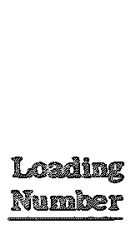 } & \multirow{4}{*}{$\begin{array}{c}\text { Total Rumber } \\
\text { of Subassemblies } \\
\text { in Core } \\
\end{array}$} & \multicolumn{7}{|c|}{ 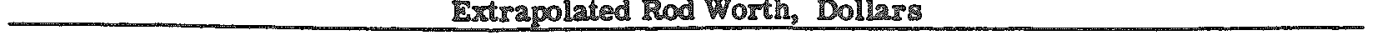 } & \multirow{4}{*}{ 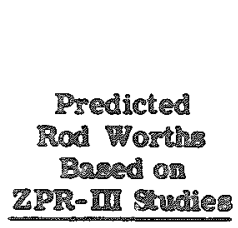 } \\
\hline & & \multirow[b]{3}{*}{ Chamel $^{\mathrm{C}}$} & \multicolumn{6}{|c|}{ Plotting Plethod } & \\
\hline & & & \multicolumn{2}{|c|}{$\mathrm{Co} / \mathrm{C}_{\mathrm{H}}$ VE. $\mathrm{N}$} & \multicolumn{2}{|c|}{$\sqrt{\mathbb{N}} \cdot \mathrm{C}_{\mathrm{O}} / \mathrm{C}_{\mathrm{W}} \mathrm{VE}$} & \multicolumn{2}{|c|}{ 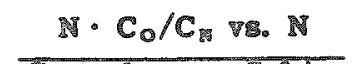 } & \\
\hline & & & $\begin{array}{l}\text { Control } \\
\text { Rade (2) } \\
\end{array}$ & $\begin{array}{r}\text { Sales } \\
\text { Rode (7) } \\
\end{array}$ & $\begin{array}{l}\text { Conkrol } \\
\text { rods (2) } \\
\end{array}$ & $\begin{array}{c}\text { Salety } \\
\text { Rodis (7) } \\
\end{array}$ & $\begin{array}{l}\text { Control } \\
\text { roode (2) }\end{array}$ & $\begin{array}{r}\text { Salety } \\
\text { Rods (7) } \\
\end{array}$ & \\
\hline 2 & 66 & $\frac{1}{4}$ & $\begin{array}{c}0.13 \\
\text { (Negative) }\end{array}$ & $\begin{array}{l}1.52 \\
2.97\end{array}$ & $\begin{array}{c}0.20 \\
\text { (Negative) }\end{array}$ & $\begin{array}{l}2.28 \\
\text { 4. } 62\end{array}$ & $\begin{array}{c}0.05 \\
\text { (Regative) }\end{array}$ & $\begin{array}{r}3.928 \\
11.22\end{array}$ & \\
\hline 4 & ำ & $\frac{1}{A}$ & $\begin{array}{l}0.10 \\
0.30\end{array}$ & $\begin{array}{l}\text { 2. } \\
\text { 2. } 1.4\end{array}$ & $\begin{array}{c}\text { (Negative) } \\
\text { I.06 }\end{array}$ & $\begin{array}{l}\text { 4. } 29 \\
3.30\end{array}$ & $\begin{array}{l}0.10 \\
0.98\end{array}$ & $\begin{array}{l}6.60 \\
3.96\end{array}$ & 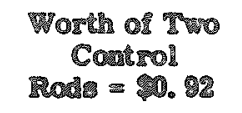 \\
\hline 6 & 87 & 1 & $\begin{array}{l}0.33 \\
0.17\end{array}$ & $\begin{array}{l}1.52 \\
4.82\end{array}$ & $\begin{array}{l}0.33 \\
0.17\end{array}$ & $\begin{array}{l}\text { 1. } 98 \\
4.95\end{array}$ & $\begin{array}{l}0.34 \\
0.10\end{array}$ & $\begin{array}{l}2.15 \\
6.27\end{array}$ & \\
\hline 2 & 93 & $\frac{1}{4}$ & $\begin{array}{l}0.53 \\
0.56\end{array}$ & $\begin{array}{l}5.61 \\
5.50\end{array}$ & $\begin{array}{l}0.83 \\
0.68\end{array}$ & $\begin{array}{l}\text { 6. } 60 \\
\text { 6. } 29\end{array}$ & $\begin{array}{l}0.23 \\
0.21\end{array}$ & $\begin{array}{l}3.25 \\
7.22\end{array}$ & Tads $=12.15$ \\
\hline 1 & 97 & $\begin{array}{l}1 \\
\mathrm{~A}\end{array}$ & $\begin{array}{l}0.62 \\
0.76\end{array}$ & $\begin{array}{l}7.26 \\
5.28\end{array}$ & $\begin{array}{l}0.76 \\
0.83\end{array}$ & $\begin{array}{l}9.5 \% \\
6.93\end{array}$ & $\begin{array}{l}0.73 \\
0.23\end{array}$ & $\begin{array}{l}13.20 \\
7.2060\end{array}$ & \\
\hline
\end{tabular}

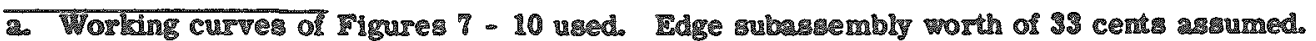

b. Ploteing Method No. 2, Co/C VB. $\sqrt{\mathbb{N}}$, was not analyzed for rod womb.

c. Only the data from the in-core channel and a typical ou-or-core changel were analyzed. 
The other position was left with a dummy still in place. The four IRB subassemblies were added in the positions shown in Figure 6. Reactivity measurements were made before and after the first one was inserted in position P01-P06, and after the remaining group of three were inserted in positions P06-P00, N06-P00 and N05-P04. The worth of the first IRB subassembly added was found to be approximately +2.60 cents, and the average worth in the group of three was +3.12 cents per subassembly. These values agree well with the predicted values of 2 to 3 cents. ${ }^{3}$

\section{Effect of Sodium Coolant Elow Rate on Reactivity}

During the final stages of the loading to criticality, a test was performed in which measurements were made to determine whether any large reactivity effect could result from the pressure differential across the core resulting from changes in primary sodium flow. The test was conducted first with a loading of 93 core subassemblies and repeated after 96 subassemblies had been loaded. The reactivity measurements were made by subcritical count rate techniques. Although this test was repeated with greater accuracy later in the test program, it was done in this test, before a critical mass had been assembled in the reactor, to verify that no large reactivity effect could result from changes in sodium flow. The possible phenomena of interest were the presence of entrained gas in the coolant and/or core deformation. The test was conducted with primary pump flows ranging from pony-motox flow to full flow. It was also done with the overflow pump on and off to see whether this introduced any gas into the core. In all cases investigated, no change in the subcritical count rate could be detected. The accuracy of the measurements was such that the minimum reactivity change that could be measured was approximately \pm 3 inhours. Based on this, it was concluded that no large reactivity effect due to flow existed in the reac. tor. A subsequent report will discuss a repetition of these measurements under critical reactor conditions. 


\section{CONCLUSIONS}

The loading to critical of the Enrico Fermi reactor progressed smoothly from the beginning to end. The fuel loading operations went according to the schedule determined by preoperational experience. Reactor temperature control was easily and accurately achieved by operation of the primary sodium pumps and cold trap. The performance of the neutron detector instrumentation and the reactor safety system was excellent throughout the loading and during the operations immediately following criticality. No spurious scrams occurred during this period. A slight perturbation in the inverse count rate curves was observed when fuel was loaded in the vicinity of the neutron source (Loading No. 6), but this perturbation was expected and presented no difficulty in the analysis of the data. The agreement between the predicted period of 180 seconds and the observed period of 178 seconds when criticality was demonstrated, is indicative of the precision which was obtained throughout the initial loading of the reactor. A high degree of confidence was established in the reactor physics characteristics and reactor operations because of the close adherence to the schedule during the loading to criticality; the versatile and uneventful operation of the reactor during the pre-critical and post-critical testing; and the close agreement between the measured and predicted critical masses, control rod calibrations, and other parameters. 


\section{REFERENCES}

1. C. E. Branyan, "Enrico Fermi Nuclear Test Procedure No. 1, Initial Loading to Criticality", APDA, 1962.

2. PRDC, "Enrico Fermi Hazards Summary Report and Technical Information", Volumes 1-7, Revised Edition, March 1964.

3. C. E. Branyan, "Core A Critical Studies for the Enrico Fermi Atomic Power Plant on ZPR-III", ANI-6629, 1962.

4. F. S. Kirn, "Neutron Detection with an Absolute Fission Counter", SM-36/74, I. A. E.A. Symposium on Neutron Detection, Dosimetry, and Standardization, Harwel1, England, December $10-14,1962$.

5. R. E. Mueller, "Interpretation of Measurements Made with Neutron Source in Reactor", APDA Internal Memorandum, P-63-198, 1963.

6. R. E. Mueller, "Effect of Revisions in Control Rod Design on Control Rod Physics", APDA Internal Memorandum, RSA-60-309, 1960. 


\section{ACKNOWLEDGEMENTS}

This work represents the combined efforts of many individuals. In addition to the regular staff members listed in the foreward, the authors would like to recognize the diligence and time devoted to the conduct of this test by K. Odajima of the Chubu Electric Power Company, Japan, who did much of the data reduction and curve plotting, and by $G$. S. Brunson and F. S. Kirn of the Staff of the Argonne National Laboratory, who made many helpful suggestions. Special recognition is given to the two consultants, R. N. Curran of ANL, Idaho and K. W. Brindly of U.K.A.E. A., Dounreay, Scotland, for their long hours and efforts contributed during the loading. The authors would also like to give credit to M. Egleme of BelgoNucleaire, Belgium, and S. B. Lundell of A.B. Atomenergi, Sweden, who aided in the early planning of the test. Finally, it should be recognized that the successful completion of the loading to criticality within the scheduled time would not have been possible without the skill and efforts of all of the operating personnel at the Fermi plant. 